\title{
Targeted Suppression of Lipoprotein Receptor LSR in Astrocytes Leads to Olfactory and Memory Deficits in Mice
}

\author{
Aseel El Hajj ${ }^{1, *}{ }^{0}$, Ameziane Herzine ${ }^{1}$, Gaetano Calcagno ${ }^{2}$, Frédéric Désor ${ }^{1}$, Fathia Djelti ${ }^{1}$, Vincent Bombail ${ }^{3}$, \\ Isabelle Denis ${ }^{3}$, Thierry Oster ${ }^{1}$, Catherine Malaplate ${ }^{1}$, Maxime Vigier ${ }^{1}$, Sandra Kaminski ${ }^{2}$, Lynn Pauron ${ }^{1}$, \\ Catherine Corbier ${ }^{1}$, Frances T. Yen ${ }^{1,+} \mathbb{D}$, Marie-Claire Lanhers ${ }^{1}$ and Thomas Claudepierre ${ }^{1, *,+} \mathbb{D}$
}

check for updates

Citation: El Hajj, A.; Herzine, A.; Calcagno, G.; Désor, F.; Djelti, F.; Bombail, V.; Denis, I.; Oster, T.; Malaplate, C.; Vigier, M.; et al. Targeted Suppression of Lipoprotein Receptor LSR in Astrocytes Leads to Olfactory and Memory Deficits in Mice. Int. J. Mol. Sci. 2022, 23, 2049. https://doi.org/10.3390/ ijms23042049

Academic Editors: Stephanie M. Cologna, Kevin R. Francis and Christopher A. Wassif

Received: 30 November 2021 Accepted: 11 February 2022 Published: 12 February 2022

Publisher's Note: MDPI stays neutral with regard to jurisdictional claims in published maps and institutional affiliations.

Copyright: (C) 2022 by the authors. Licensee MDPI, Basel, Switzerland. This article is an open access article distributed under the terms and conditions of the Creative Commons Attribution (CC BY) license (https:// creativecommons.org/licenses/by/ $4.0 /)$.
1 UR AFPA Laboratory, Qualivie Team, University of Lorraine, 54505 Vandoeuvre-lès-Nancy, France; ameziane.herzine@univ-lorraine.fr (A.H.); frederic.desor@univ-lorraine.fr (F.D.); fathia.djelti@univ-lorraine.fr (F.D.); thierry.oster@univ-lorraine.fr (T.O.); catherine.malaplate-armand@univ-lorraine.fr (C.M.); maxime.vigier@univ-lorraine.fr (M.V.); lynn.pauron@univ-lorraine.fr (L.P.); catherine.corbier@univ-lorraine.fr (C.C.); frances.yen-potin@inserm.fr (F.T.Y.); marie-claire.lanhers@univ-lorraine.fr (M.-C.L.)

2 UR 7300, Stress Immunity Pathogens Laboratory, Faculty of Medicine, University of Lorraine, 54500 Vandœuvre-lès-Nancy, France; gaetano.calcagno@univ-lorraine.fr (G.C.); sandra.kaminski@univ-lorraine.fr (S.K.)

3 UMR 914, Physiology of Nutrition and Feeding Behaviour, INRAE-Agroparistech-Université Paris-Saclay, 78352 Jouy-en-Josas, France; vincent.bombail@inrae.fr (V.B.); isabelle.denis@inrae.fr (I.D.)

* Correspondence: aseel.el-hajjar@inserm.fr (A.E.H.); thomas.claudepierre@univ-lorraine.fr (T.C.); Tel.: +33-(0)4-8110-6500 (A.E.H.); +33-(0)3-7274-4152 (T.C.)

+ These authors contributed equally to this work.

\begin{abstract}
Perturbations of cholesterol metabolism have been linked to neurodegenerative diseases. Glia-neuron crosstalk is essential to achieve a tight regulation of brain cholesterol trafficking. Adequate cholesterol supply from glia via apolipoprotein E-containing lipoproteins ensures neuronal development and function. The lipolysis-stimulated lipoprotein receptor (LSR), plays an important role in brain cholesterol homeostasis. Aged heterozygote $L s r+/-$ mice show altered brain cholesterol distribution and increased susceptibility to amyloid stress. Since LSR expression is higher in astroglia as compared to neurons, we sought to determine if astroglial LSR deficiency could lead to cognitive defects similar to those of Alzheimer's disease (AD). Cre recombinase was activated in adult GlastCreERT/lsrfl/fl mice by tamoxifen to induce astroglial Lsr deletion. Behavioral phenotyping of young and old astroglial $L s r \mathrm{KO}$ animals revealed hyperactivity during the nocturnal period, deficits in olfactory function affecting social memory and causing possible apathy, as well as visual memory and short-term working memory problems, and deficits similar to those reported in neurodegenerative diseases, such as AD. Furthermore, GFAP staining revealed astroglial activation in the olfactory bulb. Therefore, astroglial LSR is important for working, spatial, and social memory related to sensory input, and represents a novel pathway for the study of brain aging and neurodegeneration.
\end{abstract}

Keywords: glia; cholesterol; olfaction; memory; astroglial activation; Alzheimer's disease

\section{Introduction}

Cholesterol transport and homeostasis are tightly regulated in the central nervous system (CNS) to ensure proper development and functioning of the brain throughout its lifetime. However, during normal aging, cholesterol homeostasis is modified. Brain cholesterol levels change in a region-specific manner, especially in the hippocampus [1] and the cortex [2], leading to a moderate reduction in total cholesterol in the brain. These changes could influence the cortical lipid raft composition during aging [3], thus affecting the synaptic functions and normal aging process of the brain [4]. Indeed, many studies have demonstrated the links between cholesterol perturbation and neurodegenerative diseases, including Alzheimer's disease (AD) [5,6]. Due to the presence of the blood-brain barrier 
(BBB) [7], the brain must rely on de novo synthesis for cholesterol [8]. Astrocytes provide neurons with cholesterol in the form of lipoproteins, which are primarily apolipoprotein (Apo)E and ApoJ containing high-density lipoprotein-like (HDL-like) particles [9]. These HDL-like particles are exported from the astrocytes via ATP-binding cassette A1 (ABCA1) and ATP-binding cassette subfamily G member 1 (ABCG1) transporters [10], where they then bind to lipoprotein receptors via ApoE and are internalized into target cells through receptor-mediated transport processes.

Lipoproteins and their receptors are key elements ensuring the tight control of cholesterol trafficking. One of the lipoprotein receptors found in the CNS is the lipolysisstimulated lipoprotein receptor (LSR). The LSR is a multimeric protein complex composed of three subunits $\left(\alpha, \alpha^{\prime}, \beta\right)$, which are activated in the presence of free fatty acids, thereby revealing a binding site that recognizes ApoB and ApoE [11]. It was first discovered in the liver [12], and later its expression in the CNS was shown [13]. The LSR plays a role in the clearance of ApoB- and ApoE-containing lipoproteins, and helps to maintain normal levels of cholesterol and triglycerides, thereby regulating tissue lipid distribution [12,14]. The consequences of complete $L s r$ inactivation cannot be studied as it provokes lethality at the embryonic stage, most likely due to brain-localized hemorrhages and a leaky BBB [15,16]. In vivo studies on aged Lsr+/- mice suggest that reduced LSR levels are associated with cognitive disturbances related to reactivity to novel environments [13]. A significant decrease in lipid droplets, which are lipid-rich cellular organelles that regulate the storage and hydrolysis of neutral lipids, including cholesterol [17], was observed in Purkinje cells of the cerebellum, together with an accumulation of filipin-labeled cholesterol in the neuronal membranes of the hippocampus, in aged Lsr +/- mice [13]. We recently detailed the regional expression profile of LSR subunits within the CNS and found specific age-induced reductions in LSR protein expression mainly in the hypothalamus, hippocampus, and olfactory bulb [18]. Moreover, we established that astroglial cells do express LSR at levels higher than those found in neuronal cells [18].

To decipher the role of astroglial LSR in the cholesterol crosstalk within the CNS, we used a conditional Cre/lox recombination system developed in a astroglia-specific transgenic mouse line that allows for temporally controlled site-specific recombination [19]. This approach depends on cell-specific expression of tamoxifen (TAM)-dependent CreERT2 recombinase. The Glast-CreERT2 (Cre) mouse line shows highest Cre-mediated recombination in astroglial cells from the cerebellum, hippocampus, and olfactory bulb, with lower activity in other brain regions and the retina [19]. In the present study, we used the mouse strain $\mathrm{Tg}$ (Slc1a3-cre/ERT2)45-72Fwp to suppress Lsr in astroglial cells at the age of 2 months following tamoxifen (TAM) treatment, to create the TAM-induced Glast-Cre lsrfl/fl (cKO) mouse model. Behavioral phenotyping to assess activity, olfaction, vision, sociability, and short- and long-term memory revealed a series of traits resembling AD. Our findings therefore demonstrate that astroglial Lsr disruption is sufficient to switch from normal to pathological aging of the CNS.

\section{Results}

\subsection{Lsr Deletion and Downregulation of Cholesterol-Related Gene Expression in cKO Mice}

The Cre mice were crossed with $l s r f l / f l$ mice to produce Cre-lsrfl/fl (Supplementary Figure S1). Two-month-old mice were treated with tamoxifen for 5 days, followed by a battery of behavioral tests at different ages (Supplementary Figure S2). No significant differences in body mass were observed between the wild-type controls (WT) and cKO groups, nor was any mortality observed during the experimental period (Supplementary Figure S3). In order to confirm the excision of the floxed Lsr gene and the consequent cholesterolrelated gene expression, we focused on brain structures exhibiting strong CRE recombinase expression in the transgenic mouse line [19], together with strong LSR expression [18]. Expression levels of Lsr mRNA were measured by RT-qPCR on total RNA fractions extracted from different brain region homogenates of 3- and 13-month-old male WT and cKO mice. In the hippocampus, total Lsr mRNA was downregulated to $0.627 \pm 0.048$-fold 
( $p=0.0014)$ when compared to WT mice at 3 months of age (Supplementary Figure S4), and to $0.385 \pm 0.053$-fold $(p=0.004)$ at 13 months of age (Figure 1Aa). This was also the case for Lsr $\alpha(0.354 \pm 0.059$-fold, $p=0.004)$, Lsr $\alpha^{\prime}(0.337 \pm 0.039$-fold, $p=0.004)$, and Lsr $\beta$ $(0.425 \pm 0.083$-fold, $p=0.035)$ subunits. This indicates that the Lsr gene was successfully excised from the GLAST-expressing astroglial cells, which was retained 11 months after TAM injections. In the olfactory bulb, a significant reduction was observed at 3 months for total Lsr mRNA ( $0.715 \pm 0,014$-fold, $p=0.0004$, Supplementary Figure $S 4)$. At 13 months of age, a significant reduction was only observed for the $\operatorname{Lsr} \beta$ subunit $(0.85 \pm 0.32$-fold, $p=0.008)$, whereas the expression of the other Lsr subunits and total RNA remained unchanged (Figure $1 \mathrm{Ab}$ ). In the cerebellum, Lsr RNA (total and subunits) remained unchanged in 13-month-old cKO mice (Supplementary Figure S5).

A a

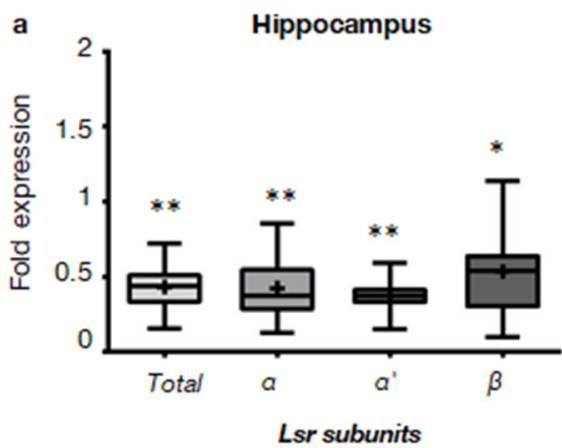

B

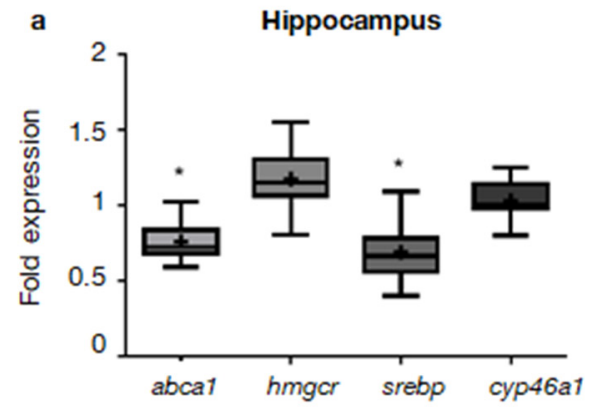

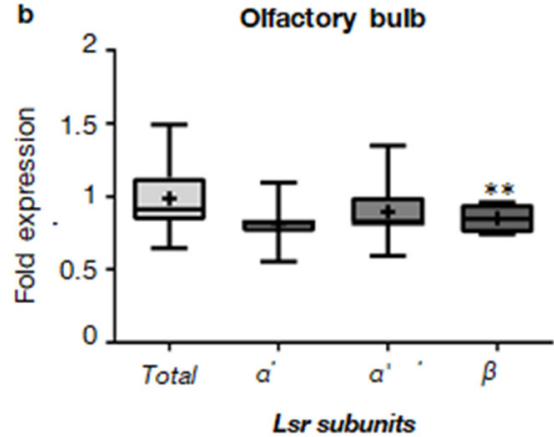

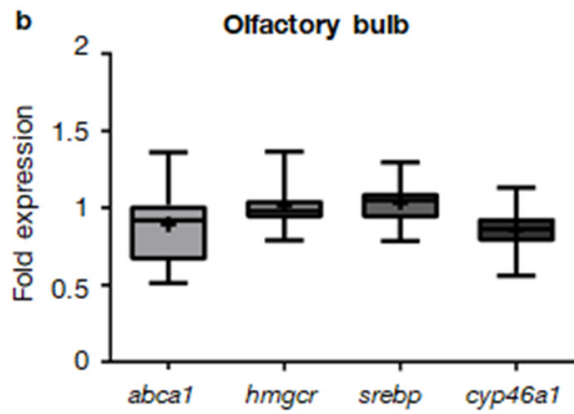

Figure 1. Modification of gene expression in astroglial Lsr cKO mice. (A) Verification of Lsr gene excision in astroglial cells using RT-qPCR. Box plot presentation of fold expression of total Lsr and different $L s r$ subunits $\alpha, \alpha^{\prime}$, and $\beta$ in 13-month-old cKO mice $(n=5)$ with respect to WT mice $(n=5)$ in the hippocampus (a) and olfactory bulb (b). (B) Box plot presentation of fold expression of cholesterolrelated gene expression in 13-month-old cKO mice $(n=5)$ with respect to WT mice $(n=5)$ in the hippocampus (a) and olfactory bulb (b). Abbreviations: abca1, ATP-binding cassette transporter 1; hmgcr, HMG CoA reductase; srebp1, sterol regulatory element-binding transcription factor 1; cyp46a1, cytochrome P450 family 46 subfamily A member 1 . Statistical significance between WT and cKO mice is shown as: ${ }^{*} p \leq 0.05,{ }^{* *} p \leq 0.01$.

In order to determine the effects of astroglia-specific Lsr deletion on brain lipid homeostasis, RT-qPCR was performed, using primers for cholesterol metabolism-related enzymes and transporters on the same samples used to verify Lsr excision (Figure 1B). In the hippocampus of 13-month-old cKO mice, where all Lsr subunits were downregulated by half, both abca1 (0.761 \pm 0.051 -fold, $p=0.025)$ and srebp $1(0.069 \pm 0.080$-fold, $p=0.047)$ were significantly downregulated as compared to WT mice. This suggests that in the hippocampus, the Lsr excision from astroglial cells disturbed cholesterol metabolism, thus affecting both lipogenesis and cholesterol efflux. Although there was a tendency for decreased $a b c a 1$ and cyp46a1 expression in the olfactory bulb, this did not reach statistical significance (Figure 1Bb). 


\subsection{Activity and Anxiety in Astroglial Lsr cKO Mice}

Home cage activity was assessed on 6-7-month-old animals. The exploratory activity of $\mathrm{cKO}$ mice was greater than that of WT mice, with a significant difference between genotypes (Figure $2 \mathrm{~A}, p<0.0001$ ), where $\mathrm{cKO}$ mice walked for longer periods of time over the course of $24 \mathrm{~h}(4.029 \pm 0.402 \mathrm{~h}$ for $\mathrm{CKO}$ mice and $2.768 \pm 0.226 \mathrm{~h}$ for WT mice, $p=0.0004$, Figure $2 \mathrm{Ab})$. This was most likely due to increased dark cycle exploration $(2.217 \pm 0.195 \mathrm{~h}$ for WT mice and $2.982 \pm 0.300 \mathrm{~h}$ for cKO mice, $p=0.028$, Figure $2 \mathrm{Ab}$ ). Interestingly, the difference between the distance traveled by $\mathrm{cKO}$ and WT mice was insignificant during the dark cycle (Supplementary Figure S6). Indeed, cKO mice $(1.208 \pm 0.063 \mathrm{~cm} / \mathrm{s})$ were generally slower than WT mice $(1.359 \pm 0.112 \mathrm{~cm} / \mathrm{s})$ during the dark cycle, $(p=0.017)$. The cKO mice did not exhibit motor coordination or equilibrium problems after careful observation (stumbling/falling events), thus ruling out the possibility of motor problems. When fine movements, such as scratching and grooming, were measured, $\mathrm{CKO}$ mice showed higher levels of such stationary activities $(1.874 \pm 0.149 \mathrm{~h})$ than WT mice $(1.389 \pm 0.088 \mathrm{~h}$, $p=0.007$ ) over a $24 \mathrm{~h}$ period. Closer inspection showed that, in their home cage environment, $\mathrm{cKO}$ mice were more active during the last $4 \mathrm{~h}$ of the dark cycle (Figure 2Aa), thus exhibiting longer periods of walking time and stationary activities.

The open field test was conducted when mice were 3 and 8 months old. At 3 months of age, WT mice spent more time in the center zone (Z3) than cKO mice, as shown by a significantly higher center/periphery ratio $(Z 3 / Z 1)$ in WT animals $(0.184 \pm 0.035)$ vs. cKO $(0.089 \pm 0.019, p=0.0095$, Figure $2 \mathrm{Ba}, \mathrm{Bc})$. In addition, data analysis revealed that $\mathrm{cKO}$ mice traveled shorter distances in the central zone Z3 when compared to WT mice (median difference of $387.9, p=0.017$, Figure 2Bd).

Data showed that at 8 months of age, WT mice actually improved with time (ratio Z3/Z1: 0.184 to $0.265, p=0.02)$. On the other hand, in cKO mice the ratio of time $\mathrm{Z3} / \mathrm{Z1}$ was left nearly unchanged between 3 - $(0.089 \pm 0.019)$ and 8-month-old mice $(0.101 \pm 0.018, p=0.74$, Figure $2 \mathrm{Ba}$ ). Thus, the difference between $\mathrm{CKO}$ and WT mice was greater at 8 months of age, and the ratio of time spent in the center over the periphery $(\mathrm{Z} 3 / \mathrm{Z} 1)$ increased significantly for WT $(0.265 \pm 0.034)$ compared to $\mathrm{CKO}(0.101 \pm 0.018, p<0.0001$, Figure $2 \mathrm{Ba})$ mice. The cKO mice spent more time (194 s) in the peripheral zone Z1 than WT mice (163 s, $p=0.038$, Figure 2Bg). However, both $\mathrm{CKO}$ and WT mice traveled the same distance in $\mathrm{Z1}$ (mean of $8131 \mathrm{~cm}$ for WT mice and $8397 \mathrm{~cm}$ for $\mathrm{cKO}$ mice, Figure 2Bh). This indicates that $\mathrm{cKO}$ mice remained in $\mathrm{Z} 1$ for longer periods of time. When comparing the time ratio Z3/Z1 in both genotypes with age, a highly significant genotype effect $(p<0.0001)$ was observed. Therefore, in a novel environment, $\mathrm{cKO}$ mice tended to stay at the periphery for longer periods of time when compared to WT mice, which may reflect thigmotaxis. This suggested that anxiety, or a lower motivation to explore, reflects apathy in cKO mice. The free exploratory paradigm test was next performed in order to assess mouse anxiety. No significant differences between cKO and WT mice were observed. Both groups spent similar times in new environments (Supplementary Figure S7), indicating that CKO and WT mice exhibit a similar level of anxiety. This supports the hypothesis that the different behavior of cKO mice in the open field is more likely due to apathy rather than anxiety.

\subsection{Olfaction in Astroglial Lsr cKO Mice}

The buried cookie test was performed when mice were 5 months old. During the habituation phase, in which the cookie is presented visibly to the animal, there was no significant difference between the cKO and WT mice in the time it took to notice and eat the food (Figure 3Aa). However, during the test phase, cKO mice took a 2-fold longer time period to find the buried cookie (203 $\pm 26.44 \mathrm{~s}$ ) when compared to WT mice (Figure $3 \mathrm{Ab}$, $104 \pm 20.52 \mathrm{~s}, p=0.0086$ ). In order to verify that this was not a problem linked to satiety or energy homeostasis, body mass (Supplementary Figure S3) and fasting blood glucose levels (Supplementary Figure S8) were measured. There was no significant difference between the two groups, suggesting that the decreased ability to find the buried food in cKO mice was most likely due to olfactory deficits. 

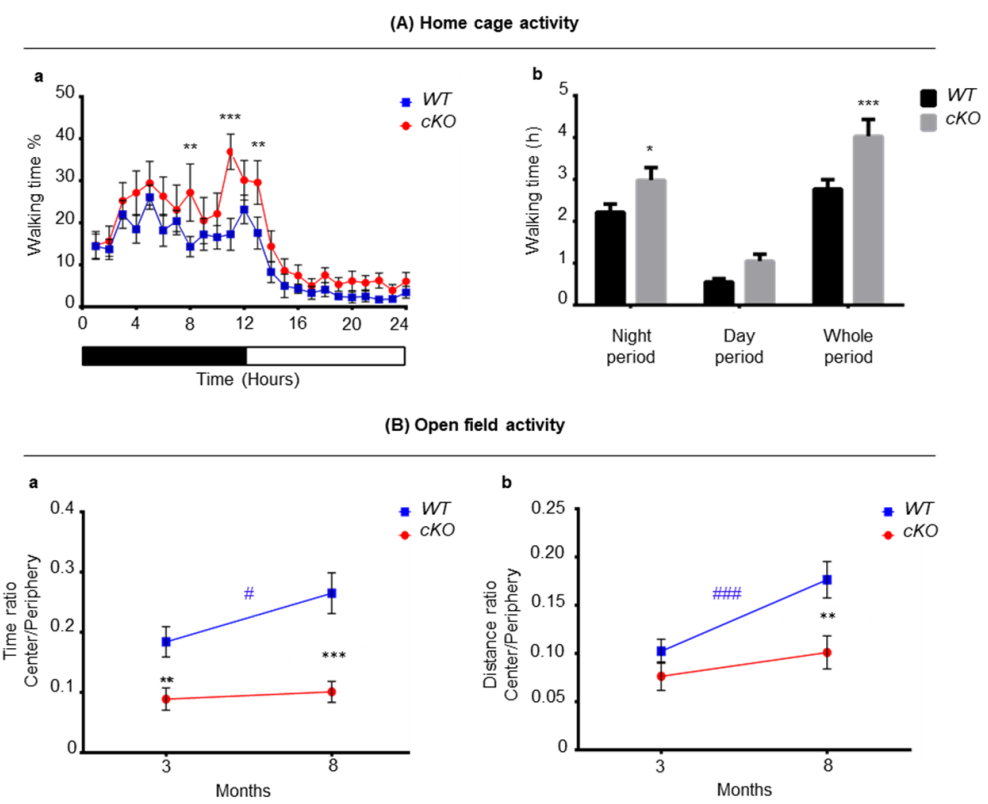

b
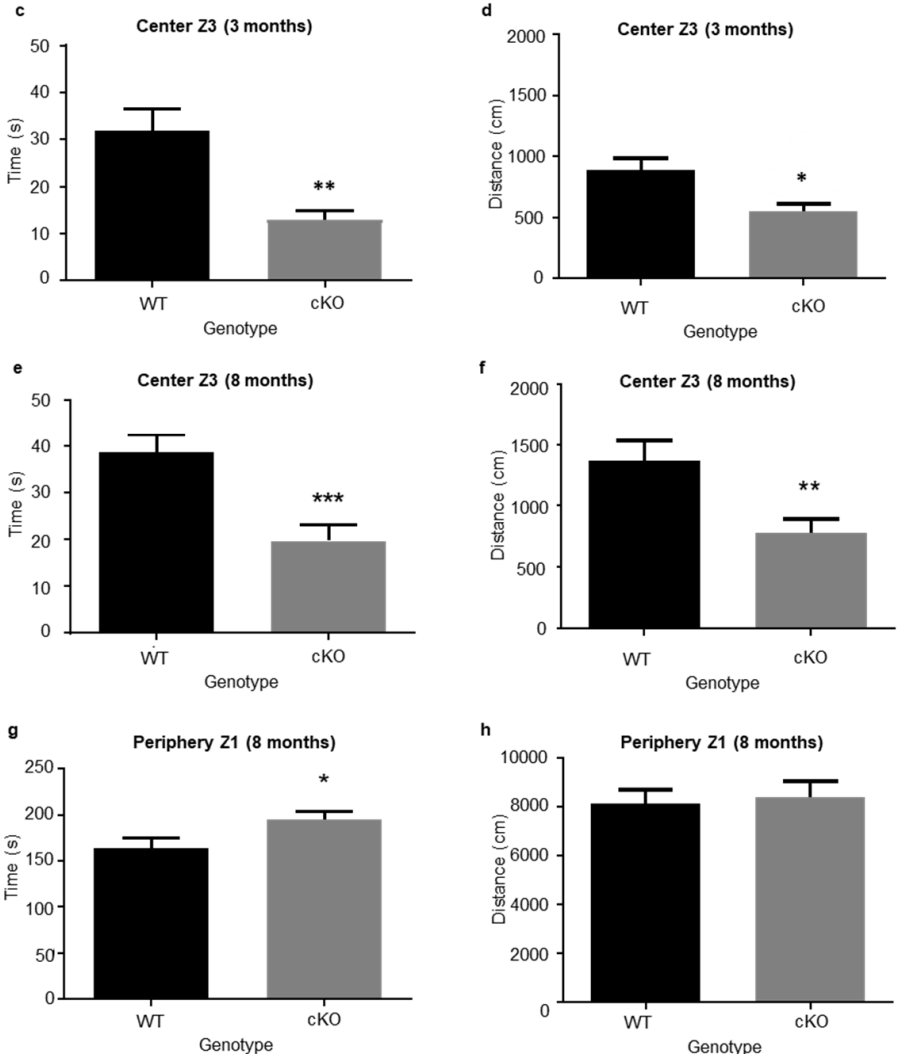

Figure 2. Activity assessment of astroglial Lsr cKO mice. (A) Home cage activity in WT $(n=18)$ and cKO $(n=16)$ mice. (a) Hourly measurements of walking time expressed as \% over a $24 \mathrm{~h}$ period. (b) Sum of walking time in hours (h) during dark cycle, light cycle, and the sum of both cycles (whole period). (B) Open field test for WT $(n=20)$ and cKO $(n=18)$ mice. (a) Time ratio spent in center (Z3) over that of periphery (Z1). (b) Distance ratio traveled in center (Z3) over that of periphery (Z1). (c) Time spent in Z3 for 3-month-old mice. (d) Distance traveled in Z3 for 3-month-old mice. (e) Time spent in Z3 for 8-month-old mice. (f) Distance traveled in Z3 for 8-month-old mice. (g) Time spent in Z1 for 8-month-old mice. (h) Distance traveled in Z1 for older 8-month-old mice. Statistical significance between WT vs. cKO mice is shown as: ${ }^{*} p \leq 0.05,{ }^{* *} p \leq 0.01,{ }^{* * *} p \leq 0.001$; comparison of age ( 3 months and 8 months) is indicated as: $\# p \leq 0.05$, \#\#\# $p \leq 0.001$. 


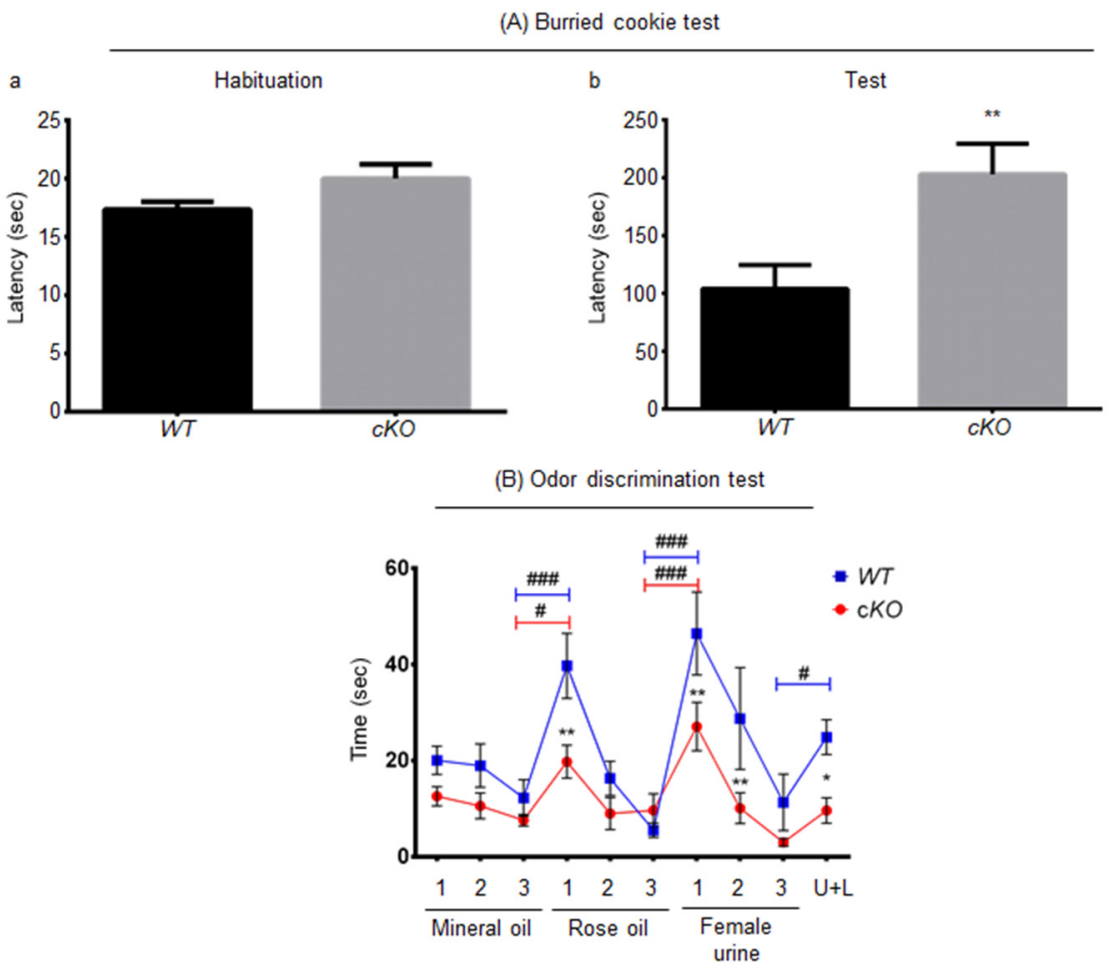

Figure 3. Olfactory assessment in cKO mice. (A) Buried cookie test results for WT $(n=20)$ and cKO $(n=18)$ mice. (a) Time taken to take and eat the visible cookie in habituation phase. (b) Time taken to find buried cookie. (B) Habituation/cross-habituation test results for WT $(n=10)$ and cKO $(n=10)$ mice. This test consists of a 5 min habituation step to the tea ball (no odor), then three $1 \mathrm{~min}$ habituation sessions to mineral oil, followed by three $2 \mathrm{~min}$ habituation sessions to rose oil, and by three 2 min habituation sessions to female urine. The test then ended with a 2 min odor discrimination step to female urine containing $1 \%$ lemon oil $(U+\mathrm{L})$. Statistical significance when comparing a single point between cKO vs. WT mice is represented as: ${ }^{*} p \leq 0.05,{ }^{* *} p \leq 0.01$. Statistical significance when comparing different sessions for same genotype are indicated as: \# $p \leq 0.05$, \#\#\# $p \leq 0.001$.

To further explore this, odor discrimination was assessed in 10-month-old mice using the habituation/cross-habituation test. There was a significant difference between $\mathrm{cKO}$ and WT mice $(p=0.0198)$. The $c K O$ and WT mice responded differently to the sequence at which odors were introduced, with a clear interaction between genotype and time $(p=0.0213)$. When comparing the exploration time of the third introduction of mineral oil and the first introduction of rose oil, WT mice and cKO mice were both able to distinguish the introduction of the new rose odor and discriminate mineral and rose oils, by spending more time sniffing the new odor source $(12.39 \pm 3.4 \mathrm{~s}$ for the third introduction of mineral oil and $38.76 \pm 6.11 \mathrm{~s}$ for the first introduction of rose odor, $p<0.0001$, for WT mice; $7.62 \pm 1.22 \mathrm{~s}$ for the third introduction of mineral oil and $19.77 \pm 3.43 \mathrm{~s}$ for the first introduction of rose odor, $p=0.016$, for $\mathrm{cKO}$ mice; Figure $3 \mathrm{~B}$ ). However, during the first introduction of rose oil, WT mice showed about twice the interest in the rose odor (38.76 $\pm 6.11 \mathrm{~s})$ when compared to cKO mice $(19.77 \pm 3.43 \mathrm{~s}, p=0.002)$. To determine whether the mice were habituated to rose oil, interest after the first (cited above) vs. third introduction of rose odor was calculated. Both WT $(6.12 \pm 1.43 \mathrm{~s}, p<0.001)$ and $\mathrm{cKO}(9.67 \pm 3.43 \mathrm{~s}$, $p=0.04)$ mice exhibited decreased interest, reflecting habituation, thus demonstrating that both mouse strains were able to memorize and recognize this specific odor. However, WT mice learned faster (Figure 3B). Both cKO (third introduction of rose odor vs. first introduction of female urine odor, $27.08 \pm 5.02 \mathrm{~s}, p=0.0004$ ) and WT (third introduction of rose odor vs. first introduction of female urine odor, $44.10 \pm 8.05 \mathrm{~s}, p<0.0001$ ) mice were able to discriminate the odors of female urine and rose oil. Although WT mice spent $17 \mathrm{~s}$ longer than $\mathrm{cKO}$ mice exploring the urine odor $(p=0.0056)$, both were habituated 
to female urine odor when comparing the first presentation to the third one (cKO mice: $3.02 \pm 0.79 \mathrm{~s}, p<0.0001$; WT mice: $10.44 \pm 5.33 \mathrm{~s}, p<0.0001$; for the third presentation of female urine odor). Interestingly, cKO mice were unable to discriminate the odor of $1 \%$ lemon oil added to female urine $(\mathrm{U}+\mathrm{L}$ ) (third presentation of female urine odor vs. $\mathrm{U}+\mathrm{L}, 9.65 \pm 2.65 \mathrm{~s}, p=0.1859$ ), unlike WT mice (third presentation of female urine odor vs. $\mathrm{U}+\mathrm{L}, 24.89 \pm 3.25 \mathrm{~s}, p=0.011$ ). In addition, WT mice explored the female urine with $1 \%$ lemon oil $15 \mathrm{~s}$ longer than $\mathrm{cKO}$ mice $(p=0.0175)$. In conclusion, $\mathrm{cKO}$ mice were able to smell and discriminate odors from very different sources, but showed less ability to discriminate subtle odor changes, such as $1 \%$ lemon oil in urine, and spent less time sniffing new odors, suggesting a lack of interest or motivation.

\subsection{Memory in Astroglial Lsr cKO Mice}

During the first session (S1) of the object recognition test, 4.5-month-old cKO and WT mice spent almost the same time exploring objects $A$ and $B$, which are sets of similar objects (WT mice: $19.72 \pm 2.36 \mathrm{~s}$ and $18.35 \pm 2.04 \mathrm{~s}$ for the objects $\mathrm{A}$ and $\mathrm{B}$, respectively; $\mathrm{CKO}$ mice: $13.51 \pm 2.70 \mathrm{~s}$ for object $\mathrm{A}$ and $12.25 \pm 2.14 \mathrm{~s}$ for object B) (Figure $4 \mathrm{a}$ ). However, there was a clear genotype effect, since cKO mice spent less total time exploring than WT mice during the first session (Figure $4 b, p=0.03$ ). Nevertheless, the object effect was insignificant for both cKO and WT mice, with no genotype-object interaction, indicating that cKO mice had no visual problems in localizing the object, but showed less interest than WT mice to this inanimate stimulus. At both $4.5(38.08 \pm 4.22 \mathrm{~s}$ for WT mice and $25.76 \pm 4.69 \mathrm{~s}$ for cKO mice, $p=0.03)$ and 9 months of age $(44.98 \pm 3.60 \mathrm{~s}$ for WT mice and $28.07 \pm 3.15 \mathrm{~s}$ for cKO mice, $p=0.003)$, there was a clear genotype effect $(p=0.001)$, but no age effect and no genotype-age interaction (Figure $4 b$ ), suggesting that the behavioral profile observed was age-independent.
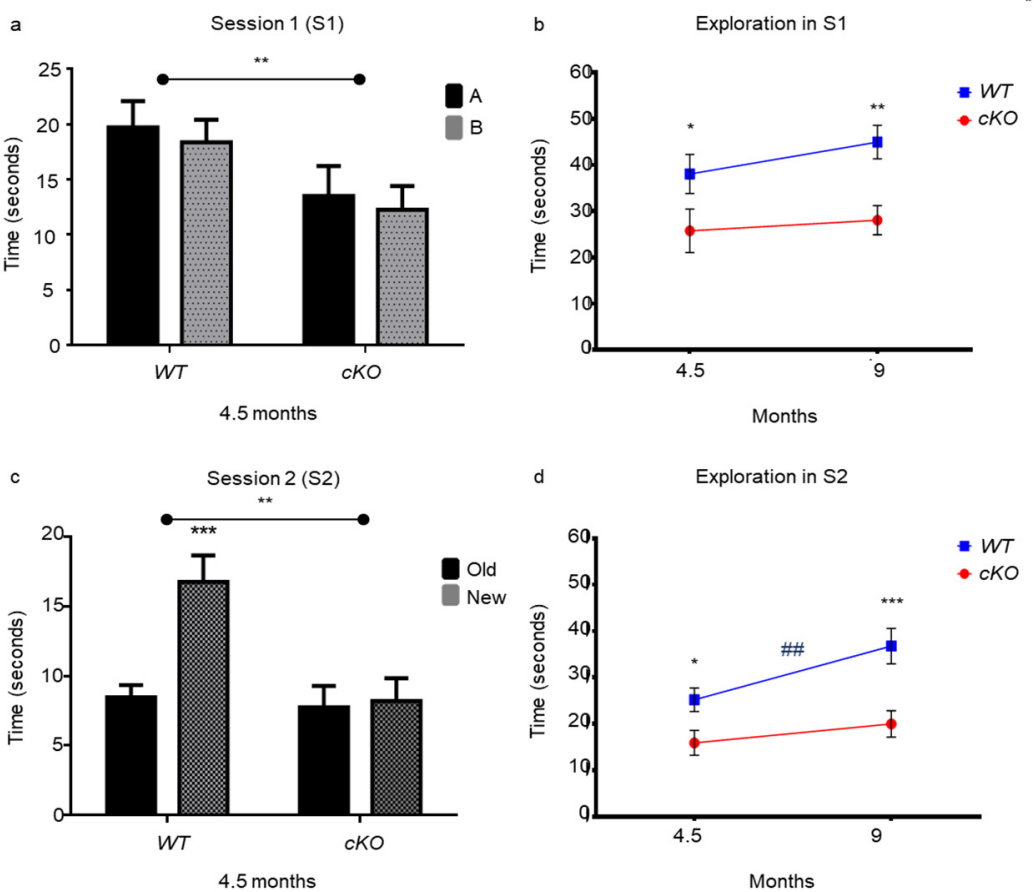

Figure 4. Vision and visual memory assessment of WT $(n=20)$ and cKO $(n=18)$ mice using object recognition test. (a) Session 1 (S1): exploration time for the same set of objects at position A and position B. (b) Total exploration time in S1 at 4.5 and 9 months of age. (c) Session 2 (S2): exploration time of an old object used in S1 and a novel object, which were positioned randomly in the apparatus. (d) Total exploration time in S2, in seconds, at 4.5 and 9 months of age. Statistical significance is shown as: ${ }^{*} p \leq 0.05,{ }^{* *} p \leq 0.01,{ }^{* * *} p \leq 0.001$. \#\# $p \leq 0.01$. 
During the second session (S2), WT mice explored the new object two times longer as compared to the old "familiar" object (old vs. new, $8.45 \pm 0.89 \mathrm{~s}$ vs. $16.77 \pm 1.92 \mathrm{~s}$, $p=0.0002)$. On the other hand, $\mathrm{cKO}$ mice explored both new and old objects for the same length of time (old vs. new, $7.75 \pm 1.52 \mathrm{~s}$ vs. $8.19 \pm 1.65 \mathrm{~s}$, Figure 4c). This indicated that 4.5-month-old cKO mice were either unable to discriminate the new object by its form and color, suggesting low visual abilities, or were unable to recall having previously seen the old object before the presentation of the new object (Figure 4c). In addition, $\mathrm{cKO}$ mice $(15.94 \pm 2.68 \mathrm{~s})$ spent less time exploring both objects than WT mice $(25.22 \pm 2.53 \mathrm{~s}$, $p=0.0165$, Figure $4 \mathrm{~d}$ ), which would suggest apathy behavior in $\mathrm{CKO}$ mice.

The sociability of the two groups was tested at 5 and 10 months of age using the threechamber sociability and novelty test. During the first session (S1), both 5-month-old cKO (stranger 1 vs. empty cage, $69.65 \pm 5.84 \mathrm{~s}$ vs. $34.22 \pm 3.004 \mathrm{~s}, p=0.0002$ ) and WT (stranger 1 vs. empty cage, $118.85 \pm 9.80 \mathrm{~s}$ vs. $26.35 \pm 2.17 \mathrm{~s}, p<0.0001)$ mice spent more time exploring stranger 1 than the empty cage (Figure 5a). However, $\mathrm{CKO}$ mice spent about half the time $(69.66 \pm 5.84 \mathrm{~s})$ exploring stranger 1 when compared to WT mice $(118.86 \pm 9.8 \mathrm{~s}$, $p<0.0001)$. There was a genotype effect $(p=0.0012)$, a subject effect $(p<0.0001)$, and a genotype-subject interaction $(p<0.0001)$. These results indicate that $\mathrm{cKO}$ mice were less social and less motivated to explore stranger 1 , when compared to WT mice.

During S2, when a second novel individual was introduced, WT mice spent more than twice the time exploring stranger 2 when compared to stranger $1(81.56 \pm 6.99 \mathrm{~s}$ for stranger 2 and $45.29 \pm 4.98 \mathrm{~s}$ for stranger $1, p<0.0001)$. On the other hand, $\mathrm{cKO}$ mice spent nearly the same time exploring strangers 1 and 2 (49.22 $\pm 516 \mathrm{~s}$ for stranger 2 and $39.27 \pm 4.74 \mathrm{~s}$ for stranger $1, p=0.224$, Figure $5 \mathrm{~b}$ ). Statistical analyses revealed a significant genotype effect $(p=0.001)$, novelty effect $(p<0.0001)$, and genotype-novelty interaction $(p=0.0215)$. Therefore, $\mathrm{cKO}$ mice were unable to discriminate the old from the new individual, indicating a deficit in social memory. As odor trace is the main parameter in individual recognition in rodents, the observed phenotype might be due to olfactory deficits, consistent with the poor performances observed with the olfactory tests described above.

This test was repeated for both groups at 10 months of age. Both cKO mice (stranger 1 vs. empty cage, $56.08 \pm 6.27 \mathrm{~s}$ vs. $23.26 \pm 3.61 \mathrm{~s}, p<0.0001$ ) and WT mice (stranger 1 vs. empty cage, $78.42 \pm 7.78 \mathrm{~s}$ vs. $28.56 \pm 3.19 \mathrm{~s}, p<0.0001)$ were attracted more to stranger 1 than the inanimate object (Figure $5 \mathrm{c}$ ). During S1, there was a genotype effect $(p=0.0025)$, a subject effect $(p<0.0001)$, but no longer a genotype-object interaction $(p=0.122)$, as was observed when the groups were younger.

During S2, there was a strong genotype effect $(p=0.007)$ and a significant genotypeobject interaction $(p=0.01)$. Although both $\mathrm{cKO}$ and WT mice spent more time exploring stranger 2 than stranger 1, WT mice explored stranger 2 for a 2.11-fold longer time period than stranger 1 ( $p<0.0001$, Figure $5 \mathrm{~d}$ ). On the other hand, cKO mice showed only 1.4-fold greater interest in stranger 2 compared to stranger 1 ( $p=0.032$, Figure $5 \mathrm{~d})$. This indicates that, although $\mathrm{cKO}$ mice were able to discriminate and retain memory of stranger 1 , it was to a lesser extent as compared to WT mice, which could indicate apathy and lack of interest in social interactions.

Indeed, WT mice exhibited greater interest to congeners than cKO mice. At 5 months of age, the total exploration time of WT mice was 1.38-fold greater than that of cKO mice (Figure 5e). This may reflect a lack of social interest in the cKO mice. With age, the total exploration time decreased significantly in cKO and WT mice in both S1 and S2 (Figure 5e,f). In S1, there was a highly significant time effect $(p<0.0001)$, and a genotype effect ( $p=0.002)$, but no genotype-time interaction (Figure 5e). During S2, there was a clear age effect $(p<0.0001)$, and genotype effect $(p=0.0003)$, and a tendency for genotype-age interaction $(p=0.068)$. This indicated a decrease in sociability and willingness to explore with age in both groups. 
a

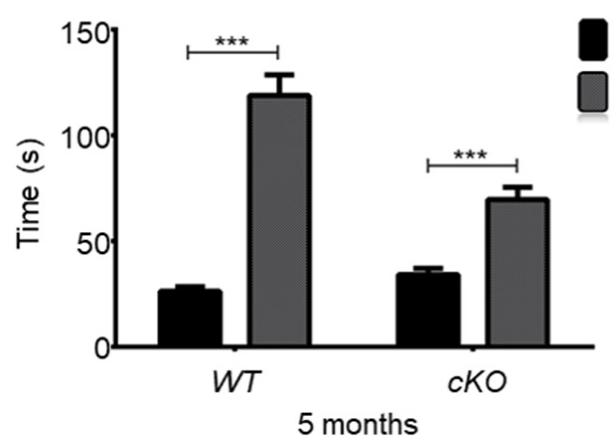

c
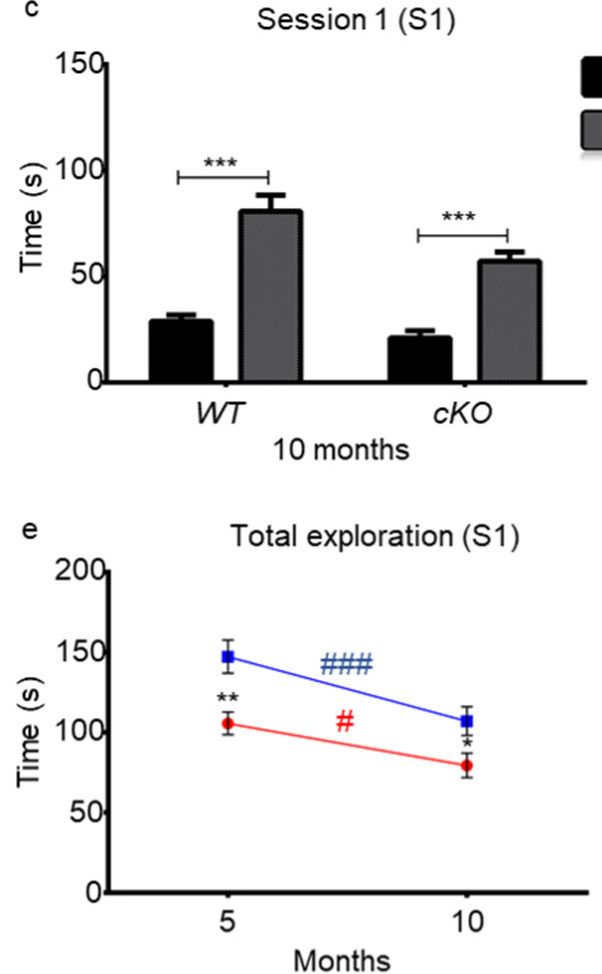

b Session 2 (S2)

Empty Stranger 1

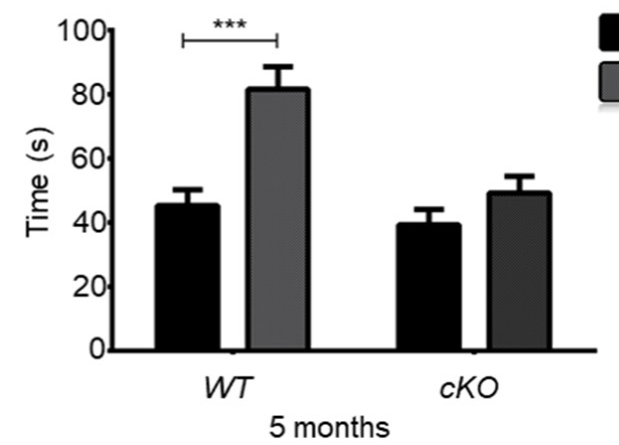

Stranger I

Stranger II

d

Empty

Stranger 1

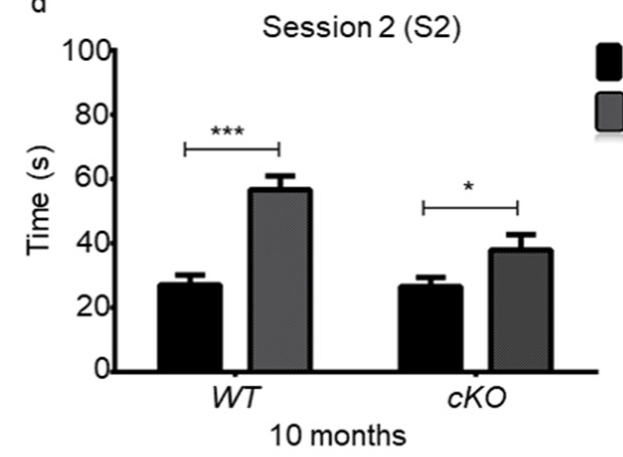

Stranger I

Stranger II

Figure 5. Sociability and social novelty assessment of WT $(n=20)$ and cKO $(n=18)$ mice. 5- $(\mathbf{a}, \mathbf{b})$ and 10- (c,d) month-old mice. (a,c) Session 1 (S1): exploration time (s) of stranger 1 vs. empty cup. (b,e) Session 2: exploration time (s) of stranger 1 used in S1 and a novel stranger. (e) Total exploration time in S1, in seconds, at 5 and 10 months of age. (f) Total exploration time (s) in S2 at 5 and 10 months of age. Statistical significance between $\mathrm{CKO}$ and WT mice at a certain time point is represented as: ${ }^{*} p \leq 0.05,{ }^{* *} p \leq 0.01,{ }^{* *} p \leq 0.001$. Statistical significance with age in cKO and WT mice is represented as: $\# p \leq 0.05$, \#\#\# $p \leq 0.001$.

To study working memory, 4-month-old animals were tested for spontaneous alternations in the Y-maze, a test to assess spatial short-term memory. The percentage of proper alternations was $68.14 \pm 2.2 \%$ for WT mice, and $55.5 \pm 2.47 \%$ for cKO mice $(p=0.0005$, Figure 6Aa). At this age, both groups had an equal total number of entries: $19 \pm 1$ for WT mice and $19 \pm 2$ for cKO mice (Figure 6Ab). Since there were no significant differences in distance and velocity between cKO and WT mice (Supplementary Figure S9A), these results indicate that $\mathrm{cKO}$ mice, from a young age, possess short-term memory problems, as they show a decreased ability to recall explored vs. unexplored arms. 


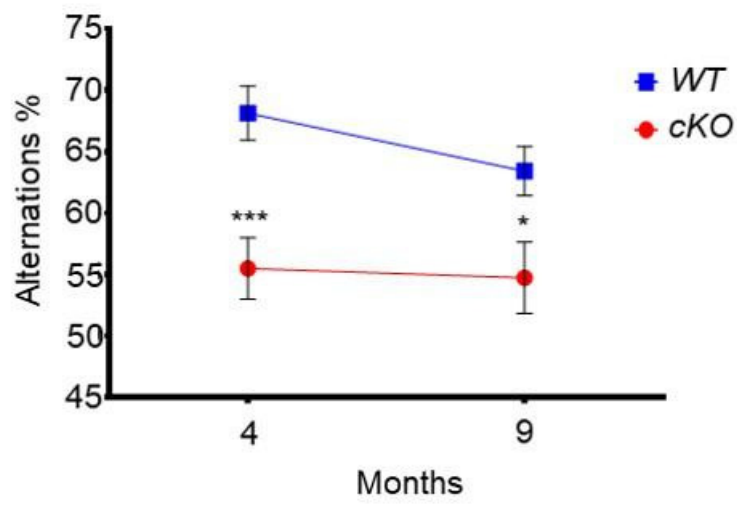

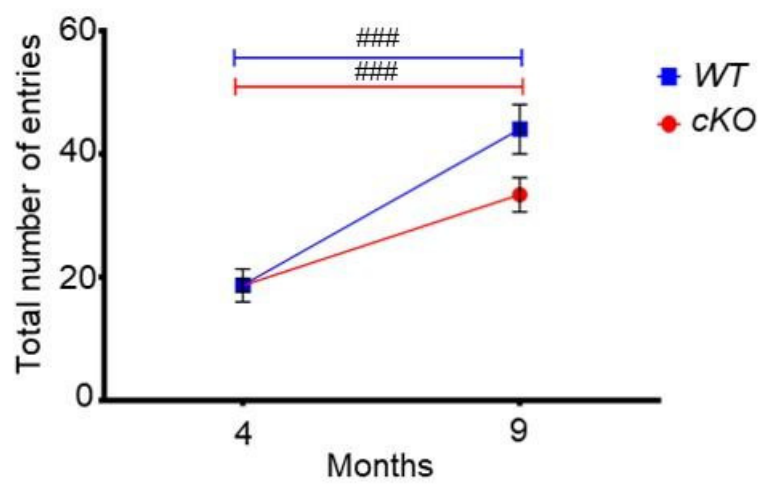

(B) Barnes maze

C

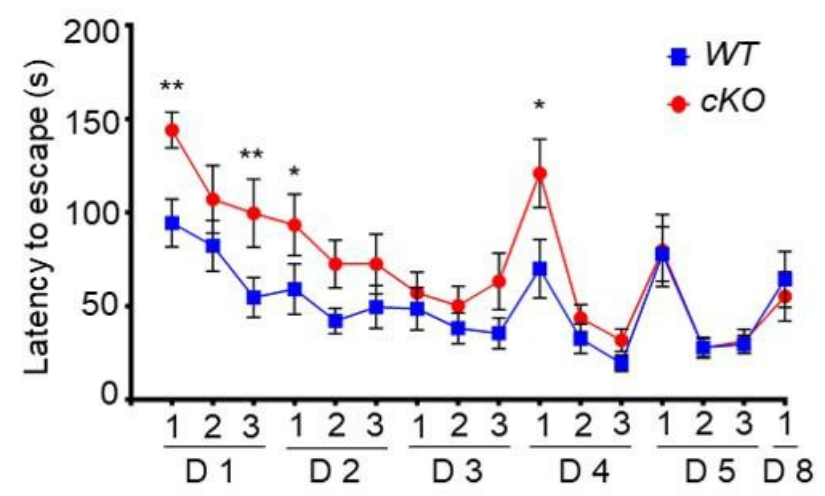

d

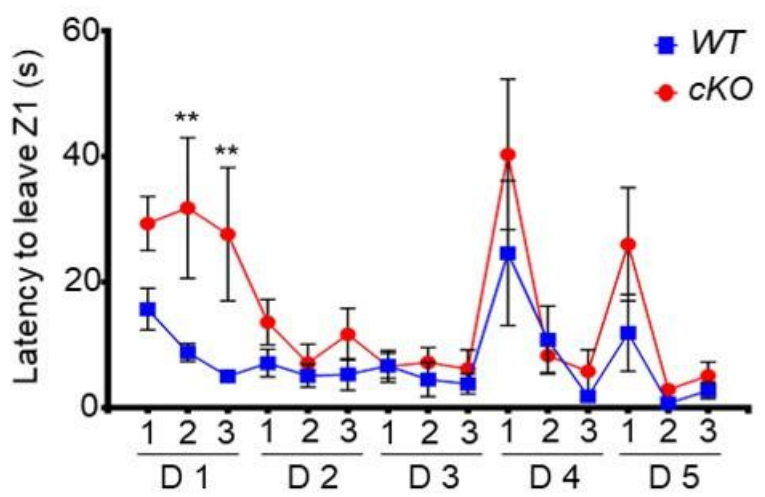

Figure 6. Short- and long-term memory assessment. (A) Y-maze for WT $(n=20)$ and cKO $(n=18)$ mice. (a) Alternation (\%) at the ages of 4 and 9 months. (b) Total number of entries at the ages of 4 and 9 months. (B) Barnes maze for WT $(n=15)$ and cKO $(n=15)$ mice. (c) The time taken to find the escape chamber, measured 3 times per day for 5 consecutive days. On day 8 , one single test session was performed to assess long-term memory. (d) Time taken to leave departure zone (Z1), measured 3 times per day for 5 consecutive days. Statistical significance between $\mathrm{cKO}$ and WT mice at different time points is represented as: ${ }^{*} p \leq 0.05,{ }^{* *} p \leq 0.01,{ }^{* * *} p \leq 0.001$. Statistical significance with time in cKO or WT mice is represented as: \#\#\# $p \leq 0.001$.

At 9 months of age, the percentage of alternations slightly decreased in WT mice to $63.17 \pm 2 \%$, whereas it remained fairly constant, but still lower, in cKO mice $(54.75 \pm 2.88 \%$, $p=0.0165$, Figure 6Aa). In addition, the measurement of the total number of entries revealed that $\mathrm{cKO}$ mice tended to enter $10 \pm 5$ less arms than WT mice $(p=0.0512$, Figure $6 \mathrm{~b})$. Again, there was no significant differences in velocity and distance between both groups (Supplementary Figure S9B); therefore, the difference in arm entries might reflect a lack of willingness to explore in cKO mice. Regarding percentage alternation, there was a clear genotype effect $(p<0.0001)$, but neither an age effect, nor a genotype-age interaction. This indicates that $\mathrm{cKO}$ mice exhibit short-term memory deficits that were not modified with age. However, a higher number of entries with age was observed in both cKO and WT mice $(p<0.0001$, Figure 6Ab), where there was a tendency for a genotype effect $(p=0.085)$, and a genotype-age interaction $(p=0.052)$. This suggests that both groups may have become more experienced with time due to frequent handling and behavioral testing. Nevertheless, 
cKO mice tended to explore less arms than WT mice, possibly reflecting a lack of motivation due to apathy.

To assess long-term memory and learning, 11-month-old animals were tested in a modified Barnes maze three times per day for five consecutive days. The time taken to escape scores gradually decreased over the training period (Figure 6Ba) in both groups of mice. There was a clear time effect $(p<0.0001)$, indicating that spatial learning was successfully achieved. When comparing trial 1 on day 1 with trial 3 on day 5 , the time to find the chamber decreased by $112.8 \mathrm{~s}$ in cKO mice (day 1 trial 1: $144.1 \mathrm{~s}$; day 5 trial 3: $31.3 \mathrm{~s}$; mean difference: $112.8 \mathrm{~s}, p<0.0001$ ), and $64.8 \mathrm{~s}$ in WT mice (day 1 trial 1: $94.4 \mathrm{~s}$; day 5 trial 3: $29.6 \mathrm{~s}$; mean difference: $64.8 \mathrm{~s}, p=0.0002)$, demonstrating an ability to learn for both cKO and WT mice. However, there was also a genotype effect $(p<0.0001)$, where on day 1 (trials 1 and 3) and day 2 (trial 1), cKO mice spent significantly more time locating the escape chamber. In trial 1 of day $1, \mathrm{cKO}$ mice spent on average $50 \mathrm{~s}$ longer than WT mice to find the escape chamber (WT mice vs. cKO mice: $94.4 \pm 12.70 \mathrm{vs}$. $144.1 \pm 9.6 \mathrm{~s}, p=0.0044)$. Interestingly, $\mathrm{cKO}$ mice on day 1 tended to take longer than WT mice to leave the departure zone Z1 (WT mice vs. cKO mice: $15.7 \pm 3.30$ vs. $29.3 \pm 4.3 \mathrm{~s}$, $p=0.062$ ) in trial 1 ; this difference became statistically significant in the two other trials of day 1 (Figure 6Bb). In trial 1 on day 4 , where the subjects were directly placed in Z1 without prior habituation to the escape chamber, the time to leave Z1 was not significantly different between $\mathrm{cKO}(40.3 \pm 12.0 \mathrm{~s})$ and WT mice $(24.6 \pm 11.5 \mathrm{~s})$ (Figure 6Bb). However, $\mathrm{cKO}$ mice spent on average $121 \pm 18.3 \mathrm{~s}$ to find the chamber, whereas WT mice spent $69.9 \pm 15.60 \mathrm{~s}(p=0.0034)$ (Figure 6Ba). This indicates that $\mathrm{cKO}$ mice demonstrated deficits when confronted with novelty that could reflect a lack of cognitive flexibility. Yet, they were able to retain information with repetition, as in subsequent trials. The time taken to escape was not statistically significant (day 4, trials 2 and 3), even when the starting zone was modified (day 5).

After stopping the test for two consecutive days, a trial was performed on day 8 to assess long-term memory. There was no significant difference between $\mathrm{CKO}$ and WT mice, where both groups spent similar times to find the chamber, suggesting no difference in long-term memory between these two groups (Figure 6Ba).

\subsection{Astroglial Activation in cKO Mice}

The olfactory bulb $(\mathrm{OB})$, hippocampal $(\mathrm{Hp})$, and cortical $(\mathrm{Cx})$ regions were identified on the sagittal sections according to the mouse brain atlas (Figure 7A). For the quantification of gliosis, glial fibrillary acidic protein (GFAP)-stained areas showing obvious shapes of a cell body were considered as GFAP + cells. We counted all GFAP+ cells in the whole field of images using three sagittal images per animal, taken from the $\mathrm{OB}, \mathrm{Hp}$, or $\mathrm{Cx}$, and compared the results obtained for $\mathrm{CKO}(n=5)$ and WT mice $(n=5)$. We observed a significant increase in the number GFAP+ cells in the OB of cKO compared to WT mice (962 \pm 40 and $669 \pm 52$ GFAP+ cells, respectively, $p=0.0079)$. No statistically significant differences were found in the Hp (WT mice: $928 \pm 38$; cKO mice: $1135 \pm 79 ; p=0.09$ ) or the Cx (WT mice: $141 \pm 20$; cKO mice: $180 \pm 17 ; p=0.3$ ) (Figure 7B). This increase in GFAP + cells can be seen in the immunohistochemical panel corresponding to the $\mathrm{OB}$ of the $\mathrm{cKO}$ mice (Figure $7 \mathrm{C}$ ). In addition, the staining intensity and shape of the cells were different between the cKO and WT sections of the OB. The cells appeared bigger and more ramified in cKO mice. The number of branches were quantified, and the results showed a significant increase in cKO mice $(7.3 \pm 0.33)$ compared to WT $(4.25 \pm 0.17, p<0.001)$ (Supplementary Figure S10). Moreover, GFAP+ cells in cKO mice exhibited larger cell bodies and cytoplasmic extensions in both the $\mathrm{OB}$ and the Hp. No major changes were noticed in the Cx. Similar images were observed in the Hp even when the total number of GFAP+ cells was unchanged. Altogether, our findings suggest astroglial activation in cKO mice. 


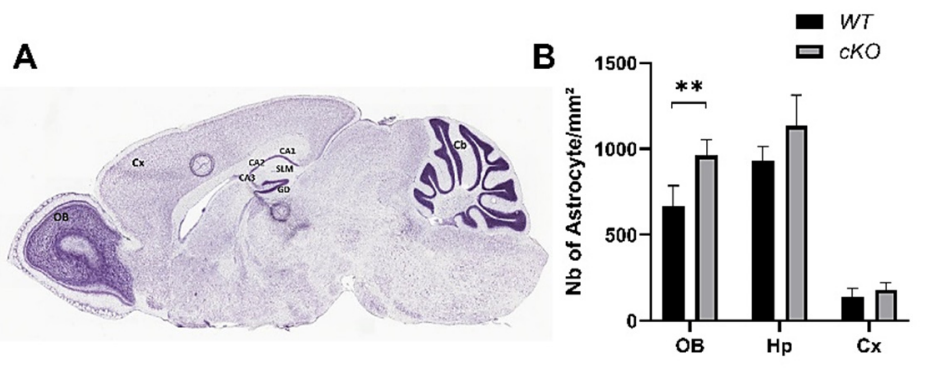

C

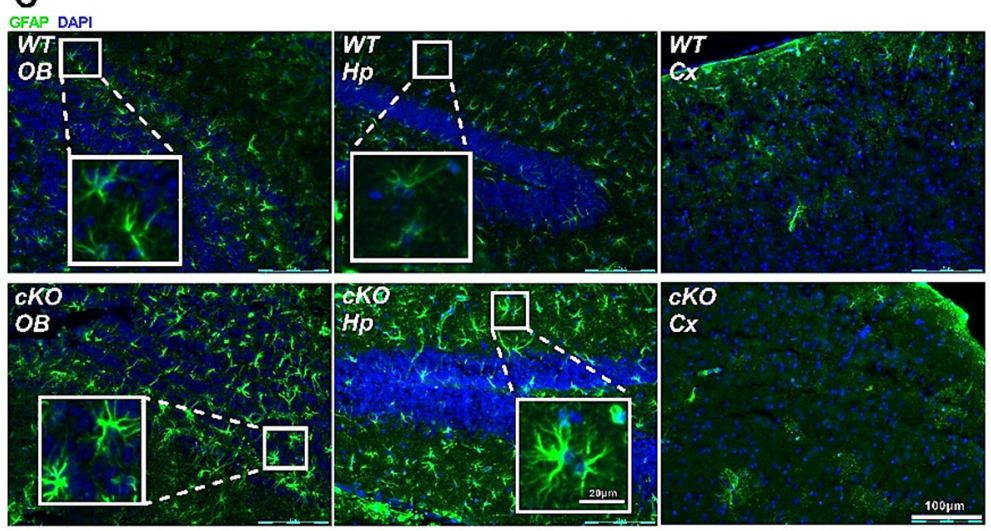

Figure 7. Astrocyte activation in astroglial Lsr in WT $(n=5)$ and cKO $(n=5)$ mice. (A) Sagittal brain section corresponding to the regions of interest. (B) Number of GFAP+ cells in different brain structures. Sagittal brain sections were stained with glial fibrillary acidic protein (GFAP). The measurements of the number of GFAP+ cells were the result of three sagittal sections analyzed per animal; the mean of all values represents one mouse. (C) Representative images from WT and cKO mice with GFAP staining (green) on sagittal sections counterstained with DAPI (nuclear blue staining). Scale bar $100 \mu \mathrm{m}$. Each value represents the mean $\pm \operatorname{SEM}(* * p<0.01)$. Abbreviations: OB, olfactory bulb; Cx, cortex; Hp, hippocampus; DG, dentate gyrus; CA, cornu ammonis; SLM, stratum lacunosum-moleculare.

\section{Discussion}

The induction of CRE enzyme activity by tamoxifen led to the excision of the Lsr gene in GLAST-expressing cells. In 3-month-old cKO mice, we detected a significant reduction in Lsr expression in both the Hp and the OB (Supplementary Figure S4). In older animals, after the battery of behavioral tests, we observed that Lsr expression was still significantly reduced in the $\mathrm{Hp}$ of $\mathrm{cKO}$ mice (Figure 1Aa), whereas the $\mathrm{OB}$ only exhibited reductions in some isoforms (Figure $1 \mathrm{Ab}$ ), or even no reduction at all, such as in the CB (Supplementary Figure S5). The discrepancies between brain regions may be due to the various levels of CRE and GLAST in the different regions. Moreover, compensatory mechanisms may occur with time in specific brain regions, leading to an overexpression of Lsr in non-glial cells, thereby masking the efficiency of the gene excision. Indeed, even if astroglial cells have been shown to express a major part of the Lsr found in the CNS [18], other cells, including neurons, may modulate their expression levels in response to tamoxifen treatment or astroglial Lsr depletion.

Nevertheless, specific in vivo suppression of $L s r$ in the astroglial cells led to the perturbation of cholesterol homeostasis in the CNS. Indeed, the significant downregulation of $\mathrm{Lsr}$ in the $\mathrm{Hp}$ was associated with the downregulation of srebp1, which is a transcriptional regulation factor of genes responsible for de novo lipogenesis, and abca1, which codes for the $A B C$ transporter responsible for cholesterol efflux and extracellular transport of lipoproteins. Therefore, LSR may play a role in modulating cholesterol synthesis and transport through SREBP1 and ABCA1. Indeed, SREBP1 mediates the activation of lipoprotein receptor promoters, such as that for LDL-R [20-22]. Further investigation is underway to 
understand how LSR downregulation is linked to perturbations in cholesterol homeostasis. Based on the genes affected in the cKO mice, as well as our previous studies showing changes in cholesterol homeostasis in $L s r+/-$ mice $[13,23]$ this may involve cholesterol metabolism-related proteins, oxysterol accumulation, and the LXR pathway. Indeed, the fine control of cholesterol trafficking in the brain is essential for proper neuronal function.

Behavioral analysis revealed several specific traits in cKO mice compared to WT animals. In addition, a series of traits were also correlated to aging in the cKO mice (Supplementary Table S1). In their environment, cKO mice remained active for longer periods of time compared to WT mice during the nocturnal period (Figure 2Aa), particularly at the beginning and at the end of the nocturnal period. This has also been observed in AD mice models, in which mice were found to be hyperactive during the nocturnal phase [24-26]. In a novel environment, cKO mice tended to stay in the peripheral zone for longer periods of time when compared to WT mice, which can be a sign of thigmotaxis. Nevertheless, they traveled the same distance at the periphery, which indicates longer immobile periods at the periphery. Together, the observed immobility and thigmotaxis could reflect a form of anxiety. However, the results of the free exploratory paradigm excluded anxiety behavior in cKO mice. Instead, cKO mice exhibited signs of apathy. Interestingly, apathy is also considered to be an early marker for neurodegenerative diseases. In addition, patients with mild cognitive impairment (MCI) exhibiting apathy are at a greater risk of developing AD compared to those with no neuropsychiatric symptoms [27].

The cKO mice were able to visualize objects and visual cues, since they explored the same set of objects for a nearly equal amount time (Figure $4 \mathrm{a}$ ). Furthermore, they were able to visualize the geometric cues in the Barnes maze to find the escape chamber (Figure 6c). However, they were unable to memorize or discriminate between an old and a new object (Figure 4c). They also showed a lower percentage of alternation in the Y-maze than the controls, indicating a deficit in recalling previously visited arms (Figure 6a). Taken together, these results suggest that visual and working memory were affected in our animals. They were able to navigate and explore their environment as they received sufficient visual sensorial stimulation, and did not suffer from locomotor problems. However, they were unable to retain information sufficiently or properly to achieve a specific task with the same efficiency as WT animals. Visual and working memory deficits are early markers of ongoing neurodegenerative processes in AD [28-30]. Impaired visual recognition memory and working memory decline are markers for MCI and its evolution towards AD [31,32]. In our animals, the working memory performance was lower in cKO mice than in WT mice, both in young and older animals; however, while it declined in WT mice, reflecting a normal aging process, it appeared more stable in cKO mice, suggesting cognitive restructuring or neuroplasticity.

With regards to olfaction, $\mathrm{cKO}$ mice took twice the time to find the buried cookie as compared to controls. In addition, they spent less time sniffing new odors and were unable to discriminate between subtle odors. Our results indicate that olfactive memory exists in cKO mice, but it is less efficient than in WT mice. This impaired sensorial entry, essential for rodent identification, might have caused cKO mice to engage less in social interactions than WT mice, thus explaining the lower sociability of cKO mice. Interestingly, deficit in olfactory discrimination is an important early diagnostic tool for neurological disorders [33]

In most tests, cKO mice displayed apathetic-like behavior. In addition, 11-month-old cKO mice also showed low cognitive flexibility and a lack of motivation to explore the novel surroundings, which could be overcome by repetitive introduction to the aversive environment of the Barnes maze. Low cognitive flexibility and lack of motivation are two well-documented behaviors found in AD patients [34,35].

The results of this study show that astroglia-specific deletion of Lsr led to a series of defects affecting $\mathrm{cKO}$ behavior. Some of these behavioral traits are found in neurodegenerative diseases, including MCI and AD [36]. The mechanisms underlying the observed phenotypes following $L s r$ deletion remain to be deciphered. However, ApoE $\varepsilon 4$ is a strong $\mathrm{AD}$ risk factor [37], and represents a potential link between lipoprotein trafficking, choles- 
terol homeostasis, and neurodegenerative processes. It has been suggested that poor the loading ability of ApoE $\varepsilon 4$ lipoproteins may lead to deficient $\beta$-amyloid clearance and cholesterol trafficking in AD patients, leading to synaptic dysfunction, destruction, and neuronal loss, thereby triggering glia cell activation and inflammatory processes [38-42]. Here, we observed an increased number of GFAP+ cells in the olfactory bulb, and changes in astrocyte morphology in the olfactory bulb and the hippocampus, suggesting astroglial activation in these brain regions (Figure 7). Interestingly, both structures are involved in the main behavioral traits identified as dysfunctional in cKO mice, suggesting that astrogliosis could contribute to the observed phenotypes. In addition, qPCR analysis revealed a significant decrease in brain-derived neurotrophic factor (BDNF) in the OB of cKO mice (Supplementary Figure S11). BDNF is a neurotrophic factor with anti-inflammatory and neuroprotective properties [43]. The inherently higher astroglia reactivity associated with Lsr depletion in these cells may further exacerbate neurodegenerative events in a process involving inflammatory signals yet to be deciphered. A link between cholesterol perturbation and inflammation has been shown in Niemann-Pick type C disease, a lysosomal storage disorder in which cholesterol accumulation leads to microglial activation and inflammatory processes, leading to neuronal death in the olfactory bulb, causing olfactory dysfunction [44]. It is possible that a similar mechanism may occur in the OB of $\mathrm{cKO}$ mice, where the deletion of $L s r$ in astroglial cells causes cholesterol perturbation, astrocyte proliferation and activation, inflammatory processes, and, ultimately, olfactory dysfunction. Additional studies are underway to confirm this hypothesis.

We postulate that astroglial LSR may play a role in the feedback control of cholesterol synthesis, limiting circulating cholesterol in brain extracellular fluid, thus maintaining cholesterol homeostasis. LSR deficiency might lead to the dysregulation of cholesterol efflux from astrocytes.

Taken together, our previous studies and current observations demonstrate LSR as a pivotal element in astrocytes involved in normal brain aging. We therefore propose that LSR represents a novel pathway to study the link between cholesterol trafficking, astrogliosis, neuroinflammation, and neurodegenerative processes.

\section{Materials and Methods}

\subsection{Animals}

Animal studies were conducted in accordance with the European Communities Council Directive (EU 2010/63) for the use and care of laboratory animals. All experimental procedures were carried out in accordance with the ethical committee CELMEA N ${ }^{\circ} 066$ (authorization number: APAFIS \#12079-201711081110404). Animals were housed in certified animal facilities (\#B54-547-24) of the Bioavailability-Bioactivity (Bio-DA) platform, with a mean temperature of $21-22^{\circ} \mathrm{C}$ and relative humidity of $50 \pm 20 \%$, and provided a standard chow diet (Envigo Teklad, Gannat, France) and water ad libitum. A reverse $12 \mathrm{~h}$ light (midnight-noon)/dark (noon-midnight) cycle was used to allow for behavioral tests during the active nocturnal phase. Floxed $l s r f l / f l$ mice were generated and obtained from the Mouse Clinical Institute (ICS, Illkirch, France). Mice expressing Cre-recombinase under an inducible GLAST promoter, Tg(Slc1a3-cre/ERT2)45-72Fwp, were kindly provided by Prof Franck Pfrieger. To generate conditional Lsr knockout male mice (cKO, $n=18)$, $\mathrm{Tg}$ (Slc1a3-cre/ERT2)45-72Fwp mice were crossed with lsrfl/fl mice; outbred males and females carrying both the Cre allele and the floxed Lsr allele were then crossed with homozygous $l s r f l / f l$ mice to obtain mice with the Cre allele and homozygous for floxed Lsr (Supplementary Figure S1). Wild-type male mice $(\mathrm{WT}, n=20)$ with the same genetic background (C57BL/6J) were used as controls (Charles River, Saint Germain Nuelles, France).

\subsection{Tamoxifen (TAM)-Induced Activation of CreERT2}

TAM (Sigma, St Louis, MO, USA) was dissolved in a 9:1 (v/v) sunflower oil (Sigma) and ethanol (Carlo Erba Reagents, Val de Reuil, France) at a concentration of $15 \mathrm{mg} / \mathrm{mL}$ at $37^{\circ} \mathrm{C}$, and then sterile-filtered and stored for up to 7 days at $4{ }^{\circ} \mathrm{C}$ in the dark. A $23 \mathrm{G}$ needle 
tuberculin syringe (Henke Sass Wolf, Tuttlingen, Germany) was used for intraperitoneal injections. At the age of 8 weeks, all mice were injected for 5 consecutive days (every $24 \mathrm{~h}$ ) with $150 \mu \mathrm{g}$ of TAM per $\mathrm{g}$ of body weight [19]. Each mouse was randomly chosen from a different litter to avoid any litter-specific bias.

\subsection{Behavioral Tests}

Two weeks after TAM induction, behavioral tests were performed over an 8 months period using the same mice throughout the entire study (Supplementary Figure S2). The open field test (OFT) was performed on 3- and 8-month-old mice, object recognition test (ORT) on 4.5- and 9-month-old mice, the Y-maze on 4- and 9-month-old mice, buried cookie test on 5-month-old mice, three-chamber sociability and social novelty test (C3C) on 5- and 10-month-old mice, home cage activity test on 6-month-old mice, color discrimination on 10-month-old mice, free exploration on 10-month-old mice, Barnes maze on 11-month-old mice. All the mentioned tests were performed $1 \mathrm{~h}$ after the beginning of the dark cycle under red light.

\subsubsection{Activity and Anxiety \\ Home Cage Activity Test}

Home cage activity test was performed at the age of 6-7 months on cKO mice $(n=16)$ and WT mice $(n=18)$. General activity, including walking time and fine movements, was measured by monitoring mice, using the Promethion High-Definition Behavioral Phenotyping System (Sable Instruments, Inc, Las Vegas, NV, USA), over a period of $24 \mathrm{~h}$. The mice were left in their own individual cages $(308 \mathrm{~L} \times 115 \mathrm{~W} \times 120 \mathrm{H} \mathrm{cm})$, with food and water ad libitum. Instrument setup and data acquisition was conducted using MetaScreen software version 2.2.18.0, and the raw data obtained were then processed via ExpeData version 1.8.4 using an analysis script for data transformation, following Sable's system guidelines. Ambulatory and voluntary activities and animal positions were monitored simultaneously by collecting the data using the XYZ beam arrays with a beam spacing of $0.25 \mathrm{~cm}$.

\section{Open Field Test}

The open field test was performed twice at the ages of 3 and 8 months on cKO mice $(n=18)$ and WT mice $(n=20)$. The test apparatus consisted of a large circle-shaped frame (diameter, $80 \mathrm{~cm} \times$ height, $60 \mathrm{~cm}$ ), virtually divided into three different zones using the SMART software (Bioseb, Vitrolles, France), as follows: an external zone Z1 (40 cm radius), an intermediate zone $Z 2$ (26.7 cm radius), and a central zone $Z 3$ (13.3 cm radius). The apparatus was illuminated on opposite sides with two lamps, where the center (Z3) was illuminated at 120 lux and the periphery with dimmer light. Each animal was placed individually on the same side of Z1, facing the wall, and allowed to explore freely for $5 \mathrm{~min}$. After each trial, the test arena was cleaned thoroughly with 5\% $(v / v)$ ethanol solution [45]. The following parameters were recorded: time spent in each zone, total distance, average velocity, as well as number of entries into each zone.

Free Exploratory Paradigm Test

The free exploratory paradigm test was performed at the age of 10 months with $15 \mathrm{cKO}$ mice and 15 WT mice. We followed the same protocol described previously [46,47]. Briefly, the apparatus was a polyvinyl chloride box $(60 \mathrm{~L} \times 42 \mathrm{~W} \times 22 \mathrm{H} \mathrm{cm})$ covered with Plexiglas and subdivided into six equal square units interconnected by small holes. The box can also be divided into two by means of three temporary partitions. Twenty-four hours before testing, each animal was randomly placed into one half of the apparatus, which constituted the "familiar" compartment. During this time, the other compartment remained inaccessible to animals by placing partitions. The floor of the familiar compartment was covered with fresh sawdust, and the animals had ad libitum access to food and water. At the start of the test, the animals were exposed to both familiar and novel environments 
by removing the partitions without themselves being removed from the box. Then, the behavior of animals was recorded under red light for $5 \mathrm{~min}$, using a video camera in infrared mode.

\subsubsection{Olfaction}

Buried Cookie Test

The buried cookie test was performed at the age of 5 months with $18 \mathrm{cKO}$ mice and 20 WT mice $[48,49]$. On the first two days, mice were habituated to the cookie (Honey pops, Kellogg's, Limoges, France), where each mouse was given a cookie per day, and the time taken to approach and start eating the cookie was monitored. On day three, the mice were fasted 6-7 h before the test time, with free access to water. The test was carried out in the housing room of the tested mice, and in their own cages. A barrier was put in the middle of the cage, and the cookie was buried $1 \mathrm{~cm}$ under the litter on the opposite side of the cage. The test was filmed using a video camera in night mode, the barrier was removed and the time taken to find and start eating the cookie was measured.

\section{Habituation/Cross-Habituation Test}

The habituation/cross-habituation test was performed when cKO $(n=10)$ and WT $(n=10)$ mice were 10 months old to assess odor discrimination performances. This test consisted of three habituation trials, each for $1 \mathrm{~min}$, to a tea ball containing mineral oil (Sigma-Aldrich), separated by a 1 min interval each time. Odor memorization would be identified by a reduction in time spent sniffing the tea ball containing a similar odor over the three trials. Then the test was continued with three 2 min habituation trials with rose oil, separated by 1 min intervals, in order to measure the ability of the mice to perform new vs. old odor discrimination. This was followed by three 2 min habituation trials with female urine, separated by 1 min intervals, in order to identify social odor discrimination. The test then ended with a 2 min odor discrimination step using female urine containing $1 \%$ lemon oil, in order to identify fine odor discrimination abilities [48-50].

\subsubsection{Memory \\ Object Recognition Test}

The object recognition test was performed twice on 4.5- and 9-month-old cKO $(n=18)$ and WT mice $(n=20)$. It was conducted to assess vision and visual memory, and was carried out in a dimly illuminated room (25 lux), in a square opaque plastic box $(30 \mathrm{~L} \times 30 \mathrm{~W} \times 26 \mathrm{H} \mathrm{cm})$. Two different sets of objects were used, either colorful plastic blocks (Lego, Billund, Denmark) or litter-filled Falcon tubes with red caps. The test was separated into three steps, a habituation step, a familiarization session, and a visual memory and novelty session. At first, mice could habituate to the empty arena and freely investigate. In the second step, mice were left to explore two similar objects, i.e., either two Lego blocks or two litter-filled Falcons, where the objects were placed in two opposite corners of the arena; namely positions A and B (session 1, S1). After $1 \mathrm{~h}$, in the visual memory session, the former object, either a Lego block or a Falcon tube, and a new object, either a Falcon tube or a Lego block, were placed in the apparatus randomly, either in position A or B (session 2, S2). The 3-points tracking mode of the SMART video-tracking system (Bioseb, Vitrolles, France) was used to monitor the object exploration using nose-point detection. In S1 and S2, a mouse was considered to be exploring an object when its nose was directed toward, and not farther than $2 \mathrm{~cm}$ away from, the object [51].

\section{Three-Chamber Sociability and Social Novelty Test}

The three-chamber sociability and social novelty test was performed twice, at 5 and 10 months of age on cKO mice $(n=18)$ and WT mice $(n=20)$ to assess sociability and social memory. The social approach apparatus was an open box made of acrylic $(63 \mathrm{~L} \times 42 \mathrm{~W} \times 23 \mathrm{H} \mathrm{cm})$ divided into three chambers with two gray acrylic walls. Dividing walls had retractable doors allowing access into each chamber. The wire cup used to 
contain the unfamiliar mice was made of cylindrical chrome bars spaced $1 \mathrm{~cm}$ apart (height, $10 \mathrm{~cm}$; bottom diameter, $10 \mathrm{~cm}$ ). The test was conducted in a 65 lux illuminated room. Test mice were placed in the central chamber at the beginning of each 5 min phase. During the habituation phase, each of the two side chambers contained an empty inverted wire cup. During the sociability phase (session 1, S1), an unfamiliar mouse (stranger 1) was enclosed in one of the wire cups in a side chamber. The location of stranger 1 alternated between the two side chambers. During the social novelty phase (session 2, S2), a new unfamiliar mouse (stranger 2), from a different cage than stranger 1, was enclosed in the wire cup that had remained empty during the sociability phase. Exploration of an enclosed mouse or an empty wire cup was defined as when a test mouse oriented toward the cup, with the distance between its nose and the cup being less than $1 \mathrm{~cm}$. The time spent in each chamber, and time spent exploring enclosed mice or empty cups, was recorded from a camera mounted overhead and analyzed afterwards by random order. All mice used as "strangers" were young male mice habituated to being enclosed in inverted wire cups in the three-chamber apparatus for 5 minutes daily on two consecutive days prior to the experiment [52].

\section{Y-Maze Test}

The Y-maze test was performed on 4 - and 9-month-old cKO mice $(n=18)$ and WT mice $(n=20)$ to assess spatial short-term memory. The 3 arms-maze was made of opaque Plexiglas, where each arm was $40 \mathrm{~cm}$ long, $16 \mathrm{~cm}$ high, and $9 \mathrm{~cm}$ wide, and positioned at equal angles. Mice were placed at the end of one arm, namely arm A, before starting the experiment countdown. The series of arm entries were recorded visually, and arm entry was validated when the hind paws of the mouse were completely placed in the arm. Spontaneous alternation behavior was monitored during a $5 \mathrm{~min}$ time period. Alternation scores were calculated by analyzing overlapping triplet sets, a sequence of unique visits to the three different arms, reflecting a memorization of the already visited arms. The proper alternation percentage was calculated as the ratio of proper alternation overlapping triplets over the total number of entries, multiplied by 100 [13].

\section{Barnes Maze}

The Barnes maze was performed when cKO $(n=15)$ and WT mice $(n=15)$ were 11 months old to assess spatial learning abilities and long-term memory. The prototype used was a modified version of the initial maze [53]. It consisted of a circular, $120 \mathrm{~cm}$ wide table, with 40 randomly placed $5 \mathrm{~cm}$ diameter holes to avoid bias induced by serial search strategies usually shown by mice, and placed $40 \mathrm{~cm}$ from the ground [54]. The platform was virtually divided into four equally portioned zones using the SMART video tracker software. There were distant and proximal visual cues placed on the left, right, above, and around the platform; the visual cue " $\mathrm{X}$ " was positioned in the zone where the only escape chamber was placed. By sprinkling water and using two fans, the platform was made aversive. The test was repeated for 5 uninterrupted days with three consecutive trials per day. Each trial was ended when the mouse found the escape chamber; if the chamber was not found, the test was stopped after $3 \mathrm{~min}$. For the first three days, the mice were placed into the escape chamber for $1 \mathrm{~min}$ before the test started, to increase their motivation for finding the escape chamber during the test. Each session started in the zone opposite to the escape zone. On the fourth day, the test was conducted without the 1 min session in the escape chamber, and on the fifth day, the test sessions were launched in another zone to assess cognitive flexibility. To assess long-term memory, two days after the fifth session, a single test session was performed starting in the same launch zone as day 4.

\subsection{RNA Extraction and Real-Time (RT) Quantitative PCR ( $q P C R$ )}

At the age of 3 months, six cKO and six WT mice were sacrificed by decapitation after isoflurane anesthesia in order to preserve the integrity of the brain structure. Total RNA was extracted from OB and Hp using the NucleoSpin ${ }^{\circledR}$ RNA Plus kit (Macherey-Nagel, Düren, 
Germany). RNA was reverse transcribed using random primers, dNTP, RNAseout, DTT, and MML-V reverse transcriptase (all from Invitrogen, Cergy Pontoise, France), following the manufacturer's instructions. The qPCRs were performed in triplicate using Takyon No ROX SYBR MasterMix blue dTTP (Eurogentec, Liège, Belgium) and a Mastercycler Realplex ${ }^{2}$ Real-Time PCR System (Eppendorf, Hamburg, Germany). The cycling program was as follows: $5 \mathrm{~min}$ at $95^{\circ} \mathrm{C}, 40$ cycles of $15 \mathrm{~s}$ at $95^{\circ} \mathrm{C}$, and $45 \mathrm{~s}$ at $60^{\circ} \mathrm{C}$. The $\mathrm{qPCR}$ efficiencies were controlled with standard curves. Data were analyzed using the Pfaffl model [55]. This method was used to measure mRNA levels of total Lsr, complement component 3 (C3, which plays a central role in complement activation), S100 calciumbinding protein $\beta(\mathrm{S} 100 \beta)$, an astrocytic marker, and brain-derived neurotrophic factor (BDNF, a member of the neurotrophin family of growth factors with anti-inflammatory properties). Relative expression of transcripts of interest was standardized using the following 3 housekeeping transcripts: eukaryotic elongation factor 2 (EEF2), peptidylprolyl cis-trans isomerase A (PPIA), and eukaryotic translation initiation factor 3 subunit $\mathrm{F}$ (EIF3F). Primers (Eurogentec) used to amplify transcripts were designed in different exons to avoid the amplification of potential genomic DNA traces (Table 1). Primer specificity was checked using a Basic Local Alignment Search Tool (BLAST) search through the US National Center for Biotechnology Information (Bethesda, MD, USA).

Table 1. Sequences of RT-qPCR primers used in the study. Forward and reverse primers of the reference genes used: EEF2, EIF3F, Hprt, Pgk1, PPIA, and Tfrc. Target isoforms of Lsr: total (T), $\alpha, \alpha^{\prime}$, and $\beta$. Cholesterol metabolism genes: abca1, cyp46a1, hmgcr, and srebp1. Inflammatory and neurotrophic genes: $B N D F, C 3$, and $S 100 \beta$.

\begin{tabular}{|c|c|c|}
\hline Gene & Forward Primer $\left(5^{\prime}\right.$ to $\left.3^{\prime}\right)$ & Reverse Primer $\left(5^{\prime}\right.$ to $\left.3^{\prime}\right)$ \\
\hline Abca1 & CAACCCCTGCTTCCGTTATCCAA & GAGAACAGGCGAGACACGATGGAC \\
\hline$B D N F$ & TGGCCTAACAGTGTTTGCAG & TGTCAGCTCCACTTAGCCTC \\
\hline C3 & AGAGGCAAGTGCTGACCAGT & ACTGGCTGGAATCTTGATGG \\
\hline Cyp46a1 & GGCTAAGAAGT TGGTCCTGTTGTAAGA & GGTGGACATCAGGAACTTCTTGACT \\
\hline EEF2 & GTGGTGGACTGTGTGTCTGG & CGCTGGAAGGTCTGGTAGAG \\
\hline EIF3F & CATCAAGGCCTATGTCAGCA & AGGTCAACTCCAATGCGTTC \\
\hline $\mathrm{Hmgcr}$ & ССССАСАТTСАСТСТTGACGСТСТ & GCTGGCGGACGCCTGACAT \\
\hline Hprt & TCAGACTGAAGAGCTACTGTAATGATCA & AAAGTTGAGAGATCATCTCCACCAA \\
\hline Lsr (total) & AGTAATACACTCCACTGTCTCCCCAG & CAGGAGAATCACCATCACAGGAA \\
\hline $\operatorname{Lsr} \alpha$ & AAGATCTGGATGGGAACAACGAG & CTTCTGAGGTCCTGCCAAGG \\
\hline $\operatorname{Lsr} \alpha^{\prime}$ & AAGATCTGGATGGGAACAACGAG & CAAAGAGCCAATCAAGGACAATG \\
\hline $\operatorname{Lsr} \beta$ & AAGATCTGGATGGGAACAACGAG & CCAGCAGCATAAACAAGGACAAT \\
\hline $\operatorname{Pgk1}$ & GAGCCTCACTGTCCAAACTA & CTTTAGCGCCTCCCAAGATA \\
\hline PPIA & GTCTCCTTCGAGCTGTTTGC & GCGTGTAAAGTCACCACCCT \\
\hline Srebpf1 & GGTCCAGCAGGTCCCAGTTGT & CTGCAGTCTTCACGGTGGCTC \\
\hline$S 100 \beta$ & AACGAGCTCTCTCACTTCСT & AAAGAACTCATGGCAGGCCG \\
\hline Tfrc & GTCTTCTGTTGAAACTTGCCCA & GAAAGGTATCCСТССАACСАСТC \\
\hline
\end{tabular}

At the age of 13 months, freshly collected tissues from five cKO and five WT mice were conserved in RNAlater (Qiagen, Les Ulis, France) as per the manufacturer's instructions, and stored at $-80^{\circ} \mathrm{C}$ until use. Different brain regions were isolated, and total RNA was extracted using TRI reagent (Sigma-Aldrich), according to the manufacturer's instructions, after homogenization using $23 \mathrm{G}$ needles. RNA quantity and purity were evaluated using the Nanodrop ND-1000 spectrophotometer (Thermo Scientific; Villebon-sur-Yvette, France), and the samples with a $260 / 280 \mathrm{~nm}$ ratio $\geq 1.7$ were used for subsequent analyses. Reverse transcription was performed using $1 \mu \mathrm{g}$ of RNA in a final volume of $20 \mu \mathrm{L}$, including $0.5 \mu \mathrm{L}$ of random primers $(3 \mathrm{mg} / \mathrm{mL}), 1 \mu \mathrm{L}$ of $10 \mathrm{mM}$ dNTP mix in RNase-free water (all from Invitrogen). After denaturation of RNA samples at $65^{\circ} \mathrm{C}$ for $5 \mathrm{~min}, 4 \mu \mathrm{L}$ of buffer $(5 \times)$, $2 \mu \mathrm{L}$ of $0.1 \mathrm{mM}$ DTT, $1 \mu \mathrm{L}$ of Superscript II reverse transcriptase, and $1 \mu \mathrm{L}$ of RNase OUT (all from Invitrogen) were added, and transcribed in an Applied Biosystems 2720 thermal cycler according to the following conditions: $25^{\circ} \mathrm{C}$ for $10 \mathrm{~min}, 42{ }^{\circ} \mathrm{C}$ for $50 \mathrm{~min}$, and $70{ }^{\circ} \mathrm{C}$ for $15 \mathrm{~min}$. The cDNA from individual animals was used as a template for the PCR array using the PowerUP SYBER Green master mix from Applied Biosystems (Foster City, 
CA, USA) with the following final concentrations in a $25 \mu \mathrm{L}$ final volume: $1 \times$ Master Mix, $100 \mathrm{nM}$ forward and reverse primers, $0.4 \mathrm{ng} / \mu \mathrm{L}$ cDNA. The mix was placed in a 7500 Fast Real-Time PCR system (Applied Biosystems). The thermal cycling conditions were an initial 5 min denaturation at $95^{\circ} \mathrm{C}$, followed by 42 cycles of $15 \mathrm{~s}$ at $95^{\circ} \mathrm{C}, 1 \mathrm{~min}$ at $60^{\circ} \mathrm{C}$, and a final dissociation step. The primer specificity was determined based on the presence of a single peak in the melting curve. We followed eight target mRNA sequences (total Lsr, Lsr $\alpha, L s r \alpha^{\prime}, L s r \beta, a b c a 1, h m g c r$, srebp 1, and cyp 46a1), and their expression levels were compared to those of three reference sequences (hypoxanthine guanine phosphoribosyl transferase (Hprt) [12], phosphoglycerate kinase 1 (Pgk1), and transferrin receptor protein 1 (Tfrc1) [56]) (Table 1). Lsr primer sequences were selected using the Primer-BLAST Genbank based on Lsr gene sequence (NM_017405). Quantitation was performed by the 2^- $\Delta \Delta \mathrm{Ct}$ method [57]. The obtained results were tested for statistical significance $(p<0.05)$ using the Relative Expression Software Tool 2009 (REST Version 2.0.13). The fold changes of mRNA samples of cKO animals were compared to WT animals.

\subsection{Blood Glucose Test}

Five-month-old mice were fasted for $6 \mathrm{~h}$ before the test; water was provided ad libitum. Blood samples were collected from the central tail artery using a sterile $25 \mathrm{G}$ needle. No anesthesia was used at the time of blood sampling to avoid unequal variations between animals and avoid the effects of anesthesia on the blood glucose levels. Mice were maintained immobile in a small retainer during blood collection from the tail. Blood samples were collected by skilled personnel. The ACCU-CHEK Performa glucometer (Roche Diabetes Care France, Meylan, France) and ACCU-CHEK strips (Roche Diabetes Care France) were used to determine plasma glucose levels.

\subsection{Immunohistochemistry}

At the age of 13 months, five cKO and five WT mice were sacrificed by decapitation after isoflurane anesthesia in order to preserve the integrity of the brain structure. Brains were fixed by immersion in 4\% PAF (Sigma-Aldrich) in $100 \mathrm{mM}$ phosphate buffer solution (PBS) for $24 \mathrm{~h}$ at $4{ }^{\circ} \mathrm{C}$. Brain architecture was cryoprotected in PBS containing 30\% sucrose before embedding the whole brains in Optimum Cutting Temperature (OCT) compound (VWR, Fontenay-sous-Bois, France). For histology, $10 \mu \mathrm{m}$ thick sagittal cryosections were made using a HM550 Cryostat (Microm Microtech, Brignais, France) and collected onto Superfrost+ slides (VWR). Brain tissue sections were permeabilized and blocked using a 0.2\% Triton 100 (Sigma-Aldrich) and 30\% Cas-Block (Invitrogen) solution prepared in 1X D-PBS (Invitrogen) for about $1 \mathrm{~h}$ at room temperature. Sections were then incubated overnight at $4{ }^{\circ} \mathrm{C}$ with mouse anti-GFAP primary antibody (MAB360, Chemicon, CA, USA) used at 1:500 dilution in D-PBS containing 0,02\% Triton x100 and 3\% Casblock. After washing, this was followed by $1 \mathrm{~h}$ incubation with goat anti-mouse secondary antibody coupled to Alexa 488 fluorochrome (ref A11001, Thermo Fisher) prepared at 1:500 dilution in D-PBS. Sections were counterstained with DAPI (D9542, Sigma) used at $10 \mu \mathrm{g} / \mathrm{mL}$, then mounted in Fluoromount-G (Electron Microscopy Sciences, Hatfield, PA, USA), and left at room temperature overnight, protected from light. Slides were then examined using a fluorescence microscope (Leica Microsystems). Image analysis and measurements were performed with Image J.

\subsection{Statistical Analyses}

To verify that the behavioral data obtained followed a Gaussian distribution, we used the Kolmogorov-Smirnov normality test. After verifying that all the data were of Gaussian distribution, student's $t$-test (two tailed, unpaired) was performed to compare $\mathrm{CKO}$ and WT mouse data with one factor (genotype). Two-way analysis of variance (ANOVA) was performed to analyze data containing two different factors (example genotype $x$ time). The numerical and graphical results are presented as mean \pm standard error of the mean (SEM). The degree of statistical significance was set at a level of $p \leq 0.05\left(^{*}\right), p \leq 0.01\left(^{* *}\right)$, 
$p \leq 0.001\left({ }^{* * *}\right)$. Statistical calculations were carried out using the Statview 4.5 statistical package (Abacus Concept, Int.) and Excel 6.0 (Microsoft, Inc.).

For RT-qPCRs, the statistical data in the boxplot were obtained using REST software tool, where $(+)$ represents the mean value, the middle line represents the median, the lower (Q1) and upper (Q3) lines in the bar represent the $25 \%$ and $75 \%$ quartile, respectively. While the upper and lower lines represent the observations outside the 9-91 percentile range, data falling outside of the Q1 and Q3 range are plotted as outliers of the data.

Supplementary Materials: The following are available online at https:/ /www.mdpi.com/article/10 $.3390 /$ ijms23042049/s1.

Author Contributions: Conceptualization, A.E.H., F.T.Y., M.-C.L. and T.C.; methodology, A.E.H., A.H., G.C., F.D. (Frédéric Désorand), F.D. (Fathia Djelti), V.B. and I.D.; validation, A.E.H., A.H., G.C., F.T.Y., M.-C.L. and T.C.; formal analysis, A.E.H., A.H., G.C. and F.D.(Frédéric Désorand) investigation, A.E.H., A.H., G.C. and F.D.; resources, F.D. (Fathia Djelti), T.O., C.M., S.K., L.P., C.C., F.T.Y., M.-C.L. and T.C.; data curation, A.E.H., A.H., F.T.Y., M.-C.L. and T.C.; writing-original draft preparation, A.E.H. and A.H.; writing—review and editing, F.D. (Fathia Djelti), V.B., I.D., T.O., C.M., S.K., M.V., L.P., C.C., F.T.Y., M.-C.L., F.T.Y. and T.C.; visualization, A.E.H., A.H.; supervision, M.-C.L. and T.C.; project administration, F.T.Y., M.-C.L. and T.C.; funding acquisition, F.T.Y. and T.C. All authors have read and agreed to the published version of the manuscript.

Funding: This research was funded by the Région Lorraine and FEDER, Fondation Alzheimer, LUE IMPACT Biomolecules, and the French Ministry of Higher Education, Research and Innovation (MESRI). Funding for the creation of the Lsr flox mice was provided in part by INSERM to the Mouse Clinical Institute. A.E.H. C.G. and M.V. thesis fellowships were provided by the MESRI.

Institutional Review Board Statement: The study was conducted according to the guidelines of the Declaration of Helsinki, and approved by the Ethics Committee of the University of Lorraine (protocol APAFIS \#12079-201711081110404v2, 2 February 2018).

Data Availability Statement: Data are contained within the article or supplementary material.

Acknowledgments: The authors thank F. W. Pfrieger for providing Glast-CreERT2 mice. The authors gratefully acknowledge Marie-Christine Birling and Tania Sorg of the Mouse Clinical Institute (MCI) for the creation of the Lsr flox mice.

Conflicts of Interest: The authors declare no conflict of interest.

\section{Abbreviations}

$\begin{array}{ll}\text { ABCA1 } & \text { ATP-binding cassette transporter A1 } \\ \text { ABCG1 } & \text { ATP-binding cassette transporter G1 } \\ \text { AD } & \text { Alzheimer's disease; Apo, apolipoprotein } \\ \text { BB } & \text { blood brain barrier } \\ \text { BDNF } & \text { brain-derived neurotrophic factor } \\ \text { cKO } & \text { astroglial Lsr knock-out } \\ \text { CNS } & \text { central nervous system } \\ \text { C3 } & \text { complement component 3 } \\ \text { Cre } & \text { Cre-recombinase } \\ \text { Cx } & \text { cortex } \\ \text { Cyp46A1 } & \text { cytochrome P450 family 46 subfamily A member 1 } \\ \text { EIF3F } & \text { eukaryotic translation initiation factor } 3 \text { subunit F } \\ \text { ERT2 } & \text { estrogen receptor inducible promoter } \\ \text { fl } & \text { flox } \\ \text { EEF2 } & \text { eukaryotic elongation factor } 2 \\ \text { GFAP } & \text { glial fibrillary acidic protein } \\ \text { GLAST } & \text { glial glutamate transporter } \\ \text { hmgcr } & \text { HMG CoA reductase } \\ \text { Hp } & \text { hippocampus }\end{array}$




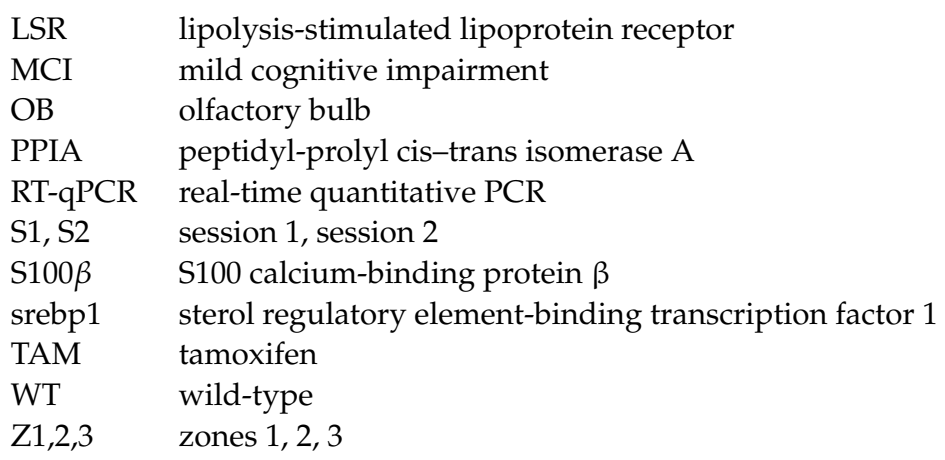

\section{References}

1. Söderberg, M.; Edlund, C.; Kristensson, K.; Dallner, G. Lipid compositions of different regions of the human brain during aging. J. Neurochem. 1990, 54, 415-423. [CrossRef]

2. Svennerholm, L.; Gottfries, C.G. Membrane lipids, selectively diminished in Alzheimer brains, suggest synapse loss as a primary event in early-onset form (type I) and demyelination in late-onset form (type II). J. Neurochem. 1994, 62, 1039-1047. [CrossRef]

3. Díaz, M.; Fabelo, N.; Ferrer, I.; Marín, R. "Lipid raft aging” in the human frontal cortex during nonpathological aging: Gender influences and potential implications in Alzheimer's disease. Neurobiol. Aging 2018, 67, 42-52. [CrossRef] [PubMed]

4. Ledesma, M.D.; Martin, M.G.; Dotti, C.G. Lipid changes in the aged brain: Effect on synaptic function and neuronal survival. Prog. Lipid Res. 2012, 51, 23-35. [CrossRef] [PubMed]

5. Martin, M.; Dotti, C.G.; Ledesma, M.D. Brain cholesterol in normal and pathological aging. Biochim. Biophys. Acta 2010, 1801, 934-944. [CrossRef] [PubMed]

6. Hicks, D.A.; Nalivaeva, N.N.; Turner, A.J. Lipid rafts and Alzheimer's disease: Protein-lipid interactions and perturbation of signaling. Front. Physiol. 2012, 3, 189. [CrossRef]

7. Pitas, R.E.; Boyles, J.K.; Lee, S.H.; Hui, D.; Weisgraber, K.H. Lipoproteins and their receptors in the central nervous system. Characterization of the lipoproteins in cerebrospinal fluid and identification of apolipoprotein B,E(LDL) receptors in the brain. J. Biol. Chem. 1987, 262, 14352-14360. [CrossRef]

8. Jeske, D.J.; Dietschy, J.M. Regulation of rates of cholesterol synthesis in vivo in the liver and carcass of the rat measured using [3H]water. J. Lipid Res. 1980, 21, 364-376. [CrossRef]

9. Fagan, A.M.; Holtzman, D.M.; Munson, G.; Mathur, T.; Schneider, D.; Chang, L.K.; Getz, G.S.; Reardon, C.A.; Lukens, J.; Shah, J.A.; et al. Unique lipoproteins secreted by primary astrocytes from wild type, apoE $(-/-)$, and human apoE transgenic mice. J. Biol. Chem. 1999, 274, 30001-30007. [CrossRef]

10. Chen, J.; Zhang, X.; Kusumo, H.; Costa, L.G.; Guizzetti, M. Cholesterol efflux is differentially regulated in neurons and astrocytes: Implications for brain cholesterol homeostasis. Biochim. Biophys. Acta 2013, 1831, 263-275. [CrossRef]

11. Bihain, B.E.; Yen, F.T. The lipolysis stimulated receptor: A gene at last. Curr. Opin. Lipidol. 1998, 9, 221-224. [CrossRef] [PubMed]

12. Yen, F.T.; Roitel, O.; Bonnard, L.; Notet, V.; Pratte, D.; Stenger, C.; Magueur, E.; Bihain, B.E. Lipolysis stimulated lipoprotein receptor: A novel molecular link between hyperlipidemia, weight gain, and atherosclerosis in mice. J. Biol. Chem. 2008, 283, 25650-25659. [CrossRef]

13. Stenger, C.; Pinçon, A.; Hanse, M.; Royer, L.; Comte, A.; Koziel, V.; Olivier, J.L.; Pillot, T.; Yen, F.T. Brain region-specific immunolocalization of the lipolysis-stimulated lipoprotein receptor (LSR) and altered cholesterol distribution in aged LSR+/mice. J. Neurochem. 2012, 123, 467-476. [CrossRef]

14. Narvekar, P.; Berriel Diaz, M.; Krones-Herzig, A.; Hardeland, U.; Strzoda, D.; Stöhr, S.; Frohme, M.; Herzig, S. Liver-specific loss of lipolysis-stimulated lipoprotein receptor triggers systemic hyperlipidemia in mice. Diabetes 2009, 58, 1040-1049. [CrossRef]

15. Mesli, S.; Javorschi, S.; Bérard, A.M.; Landry, M.; Priddle, H.; Kivlichan, D.; Smith, A.J.; Yen, F.T.; Bihain, B.E.; Darmon, M. Distribution of the lipolysis stimulated receptor in adult and embryonic murine tissues and lethality of LSR-/ - embryos at 12.5 to 14.5 days of gestation. Eur. J. Biochem. 2004, 271, 3103-3114. [CrossRef]

16. Sohet, F.; Lin, C.; Munji, R.N.; Lee, S.Y.; Ruderisch, N.; Soung, A.; Arnold, T.D.; Derugin, N.; Vexler, Z.S.; Yen, F.T.; et al. LSR/angulin-1 is a tricellular tight junction protein involved in blood-brain barrier formation. J. Cell Biol. 2015, 208, 703-711. [CrossRef] [PubMed]

17. Martin, S.; Parton, R.G. Lipid droplets: A unified view of a dynamic organelle. Nat. Rev. Mol. Cell Biol. 2006, 7, 373-378. [CrossRef]

18. El Hajj, A.; Yen, F.T.; Oster, T.; Malaplate, C.; Pauron, L.; Corbier, C.; Lanhers, M.C.; Claudepierre, T. Age-related changes in regiospecific expression of Lipolysis Stimulated Receptor (LSR) in mice brain. PLoS ONE 2019, 14, e0218812. [CrossRef]

19. Slezak, M.; Göritz, C.; Niemiec, A.; Frisén, J.; Chambon, P.; Metzger, D.; Pfrieger, F.W. Transgenic mice for conditional gene manipulation in astroglial cells. Glia 2007, 55, 1565-1576. [CrossRef] [PubMed]

20. Streicher, R.; Kotzka, J.; Müller-Wieland, D.; Siemeister, G.; Munck, M.; Avci, H.; Krone, W. SREBP-1 mediates activation of the low-density lipoprotein receptor promoter by insulin and insulin-like growth factor-I. J. Biol. Chem. 1996, 271, 7128-7133. [CrossRef] 
21. Horton, J.D.; Goldstein, J.L.; Brown, M.S. SREBPs: Activators of the complete program of cholesterol and fatty acid synthesis in the liver. J. Clin. Investig. 2002, 109, 1125-1131. [CrossRef]

22. Liu, Y.; Chen, B.P.; Lu, M.; Zhu, Y.; Stemerman, M.B.; Chien, S.; Shyy, J.Y. Shear stress activation of SREBP1 in endothelial cells is mediated by integrins. Arterioscler. Thromb. Vasc. Biol. 2002, 22, 76-81. [CrossRef]

23. Pinçon, A.; Thomas, M.H.; Huguet, M.; Allouche, A.; Colin, J.C.; Georges, A.; Derrien, A.; Lanhers, M.C.; Malaplate-Armand, C.; Oster, T.; et al. Increased susceptibility of dyslipidemic LSR+/ - mice to amyloid stress is associated with changes in cortical cholesterol levels. J. Alzheimer's Dis. 2015, 45, 195-204. [CrossRef]

24. Faure, A.; Verret, L.; Bozon, B.; El Tannir El Tayara, N.; Ly, M.; Kober, F.; Dhenain, M.; Rampon, C.; Delatour, B. Impaired neurogenesis, neuronal loss, and brain functional deficits in the APPxPS1-Ki mouse model of Alzheimer's disease. Neurobiol. Aging 2011, 32, 407-418. [CrossRef] [PubMed]

25. Filali, M.; Lalonde, R.; Rivest, S. Anomalies in social behaviors and exploratory activities in an APPswe/PS1 mouse model of Alzheimer's disease. Physiol. Behav. 2011, 104, 880-885. [CrossRef] [PubMed]

26. Djelti, F.; Braudeau, J.; Hudry, E.; Dhenain, M.; Varin, J.; Bièche, I.; Marquer, C.; Chali, F.; Ayciriex, S.; Auzeil, N.; et al. CYP46A1 inhibition, brain cholesterol accumulation and neurodegeneration pave the way for Alzheimer's disease. Brain 2015, 138, 2383-2398. [CrossRef]

27. Ruthirakuhan, M.; Herrmann, N.; Vieira, D.; Gallagher, D.; Lanctôt, K.L. The roles of apathy and depression in predicting Alzheimer Disease: A longitudinal analysis in older adults with Mild Cognitive Impairment. Am. J. Geriatr. Psychiatry 2019, 27, 873-882. [CrossRef] [PubMed]

28. Kawas, C.H.; Corrada, M.M.; Brookmeyer, R.; Morrison, A.; Resnick, S.M.; Zonderman, A.B.; Arenberg, D. Visual memory predicts Alzheimer's disease more than a decade before diagnosis. Neurology 2003, 60, 1089-1093. [CrossRef]

29. Jahn, H. Memory loss in Alzheimer's disease. Dialogues Clin. Neurosci. 2013, 15, 445-454.

30. Liang, Y.; Pertzov, Y.; Nicholas, J.M.; Henley, S.M.D.; Crutch, S.; Woodward, F.; Leung, K.; Fox, N.C.; Husain, M. Visual short-term memory binding deficit in familial Alzheimer's disease. Cortex 2016, 78, 150-164. [CrossRef]

31. Didic, M.; Felician, O.; Barbeau, E.J.; Mancini, J.; Latger-Florence, C.; Tramoni, E.; Ceccaldi, M. Impaired visual recognition memory predicts Alzheimer's disease in amnestic mild cognitive impairment. Dement. Geriatr. Cogn. Disord. 2013, 35, 291-299. [CrossRef]

32. Kirova, A.M.; Bays, R.B.; Lagalwar, S. Working memory and executive function decline across normal aging, mild cognitive impairment, and Alzheimer's disease. Biomed. Res. Int. 2015, 2015, 748212. [CrossRef]

33. Zou, Y.M.; Lu, D.; Liu, L.P.; Zhang, H.H.; Zhou, Y.Y. Olfactory dysfunction in Alzheimer's disease. Neuropsychiatr. Dis. Treat. 2016, 12, 869-875. [CrossRef] [PubMed]

34. Starkstein, S.E.; Jorge, R.; Mizrahi, R.; Robinson, R.G. A prospective longitudinal study of apathy in Alzheimer's disease. J. Neurol. Neurosurg. Psychiatry 2006, 77, 8-11. [CrossRef] [PubMed]

35. Nobis, L.; Husain, M. Apathy in Alzheimer's disease. Curr. Opin. Behav. Sci. 2018, 22, 7-13. [CrossRef] [PubMed]

36. Lyketsos, C.G.; Carrillo, M.C.; Ryan, J.M.; Khachaturian, A.S.; Trzepacz, P.; Amatniek, J.; Cedarbaum, J.; Brashear, R.; Miller, D.S. Neuropsychiatric symptoms in Alzheimer's disease. Alzheimer's Dement. 2011, 7, 532-539. [CrossRef] [PubMed]

37. Liu, C.C.; Liu, C.C.; Kanekiyo, T.; Xu, H.; Bu, G. Apolipoprotein E and Alzheimer disease: Risk, mechanisms and therapy. Nat. Rev. Neurol. 2013, 9, 106-118. [CrossRef] [PubMed]

38. LaDu, M.J.; Falduto, M.T.; Manelli, A.M.; Reardon, C.A.; Getz, G.S.; Frail, D.E. Isoform-specific binding of apolipoprotein E to beta-amyloid. J. Biol. Chem. 1994, 269, 23403-23406. [CrossRef]

39. Bales, K.R.; Du, Y.; Holtzman, D.; Cordell, B.; Paul, S.M. Neuroinflammation and Alzheimer's disease: Critical roles for cytokine/Abeta-induced glial activation, NF-kappaB, and apolipoprotein E. Neurobiol. Aging. 2000, 21, 427-453. [CrossRef]

40. Rapp, A.; Gmeiner, B.; Hüttinger, M. Implication of apoE isoforms in cholesterol metabolism by primary rat hippocampal neurons and astrocytes. Biochimie 2006, 88, 473-483. [CrossRef]

41. Klein, R.C.; Mace, B.E.; Moore, S.D.; Sullivan, P.M. Progressive loss of synaptic integrity in human apolipoprotein E4 targeted replacement mice and attenuation by apolipoprotein E2. Neuroscience 2010, 171, 1265-1272. [CrossRef]

42. Sen, A.; Alkon, D.L.; Nelson, T.J. Apolipoprotein E3 (ApoE3) but not ApoE4 protects against synaptic loss through increased expression of protein kinase C epsilon. J. Biol. Chem. 2012, 287, 15947-15958. [CrossRef] [PubMed]

43. Zhao, S.; Zhang, Z.; Xu, D.; Wang, Y.; Li, L. Selective Loss of Brain-Derived Neurotrophic Factor Exacerbates Brain Injury by Enhancing Neuroinflammation in Experimental Streptococcus pneumoniae Meningitis. Front Immunol. 2020, 11, 1357. [CrossRef]

44. Seo, Y.; Kim, H.S.; Kang, K.S. Microglial involvement in the development of olfactory dysfunction. J. Vet. Sci. 2018, 19, 319-330. [CrossRef] [PubMed]

45. Belhaj, N.; Desor, F.; Gleizes, C.; Denis, F.M.; Arab-Tehrany, E.; Soulimani, R.; Linder, M. Anxiolytic-like effect of a salmon phospholipopeptidic complex composed of polyunsaturated fatty acids and bioactive peptides. Mar. Drugs. 2013, 11, $4294-4317$. [CrossRef]

46. Misslin, R.; Ropartz, P. Effects of lateral amygdala lesions on the responses to novelty in mice. Behav. Processes. 1981, 6, 329-336. [CrossRef]

47. Elhabazi, K.; Dicko, A.; Desor, F.; Dalal, A.; Younos, C.; Soulimani, R. Preliminary study on immunological and behavioural effects of Thymus broussonetii Boiss., an endemic species in Morocco. J. Ethnopharmacol. 2006, 103, 413-419. [CrossRef] 
48. Fleming, S.M.; Tetreault, N.A.; Mulligan, C.K.; Hutson, C.B.; Masliah, E.; Chesselet, M.F. Olfactory deficits in mice overexpressing human wildtype alpha-synuclein. Eur. J. Neurosci. 2008, 28, 247-256. [CrossRef]

49. Yang, M.; Crawley, J.N. Simple behavioral assessment of mouse olfaction. Curr Protoc Neurosci. 2009, 8, 8-24. [CrossRef]

50. Meunier, N.; Raynaud, A.; Le Bourhis, M.; Grébert, D.; Dewaele, A.; Acquistapace, A.; Bombail, V. The olfactory mucosa, first actor of olfactory detection, is sensitive to glucocorticoid hormone. Eur. J. Neurosci. 2020, 51, 1403-1418. [CrossRef] [PubMed]

51. Leger, M.; Quiedeville, A.; Bouet, V.; Haelewyn, B.; Boulouard, M.; Schumann-Bard, P.; Freret, T. Object recognition test in mice. Nat. Protoc. 2013, 8, 2531-2537. [CrossRef] [PubMed]

52. Lo, S.C.; Scearce-Levie, K.; Sheng, M. Characterization of social behaviors in caspase-3 deficient mice. Sci Rep. $2016,6,18335$. [CrossRef] [PubMed]

53. Barnes, C.A. Memory deficits associated with senescence: A neurophysiological and behavioral study in the rat. J. Comp. Physiol. Psychol. 1979, 93, 74-104. [CrossRef] [PubMed]

54. Youn, J.; Ellenbroek, B.A.; van Eck, I.; Roubos, S.; Verhage, M.; Stiedl, O. Finding the right motivation: Genotype-dependent differences in effective reinforcements for spatial learning. Behav. Brain Res. 2012, 226, 397-403. [CrossRef]

55. Pfaffl, M.W. A new mathematical model for relative quantification in real-time RT-PCR. Nucleic Acids Res. 2001, 29, e45. [CrossRef]

56. Boda, E.; Pini, A.; Hoxha, E.; Parolisi, R.; Tempia, F. Selection of reference genes for quantitative real-time RT-PCR studies in mouse brain. J. Mol. Neurosci. 2009, 37, 238-253. [CrossRef] [PubMed]

57. Livak, K.J.; Schmittgen, T.D. Analysis of relative gene expression data using real-time quantitative PCR and the $2^{-\Delta \Delta C t}$ method. Methods 2001, 25, 402-408. [CrossRef] 